\title{
CLAVATA1, a regulator of meristem and flower development in
}

\section{Arabidopsis}

\author{
Steven E. Clark, Mark P. Running and Elliot M. Meyerowitz* \\ Division of Biology 156-29, California Institute of Technology, Pasadena, CA 91125, USA \\ ${ }^{*}$ Author for correspondence
}

\section{SUMMARY}

We have investigated the effects on plant development of mutations in the Arabidopsis thaliana CLAVATA1 gene. In clavata1 plants, vegetative, inflorescence and floral meristems are all enlarged relative to wild type. The apical meristem can fasciate in the more severe mutant alleles, and this fasciation can occur prior to the transition to flowering. Flowers of clavata1 plants can have increased numbers of organs in all four whorls, and can also have additional whorls not present in wild-type flowers. Double mutant combinations of clavatal with agamous, apetala2, apetala3 and pistillata indicate that
CLAVATA1 controls the underlying floral meristem structure upon which these homeotic genes act. Double mutant combinations of clavata1 with apetala1 and leafy indicate CLAVATA1 plays a role in establishing and maintaining floral meristem identity, in addition to its role in controlling meristem size. In support of this, RNA expression patterns of $A G A M O U S$ and $A P E T A L A 1$ are altered in clavatal flowers.

Key words: fasciation, flower, meristem, inflorescence, Arabidopsis, CLAVATA1

\section{INTRODUCTION}

Two key developmental processes help determine the overall aerial structure of plants. The first process is the establishment of the apical meristem structure, including the positioning of developing primordia. The second process is the specification of the identity of these developing primordia. In Arabidopsis thaliana the apical meristem generates primordia on its flanks in a phyllotactic spiral, and, as development progresses, these primordia are specified as rosette leaves with axillary shoot meristems, cauline leaves with similar meristems, or flowers (Smyth et al., 1990).

Some of the genes involved in primordium specification have been identified. Key factors specifying floral meristem identity include LEAFY (Schultz and Haughn, 1991; Weigel et al., 1992; Huala and Sussex, 1992; Weigel and Meyerowitz, 1993), APETALA1 (Irish and Sussex, 1990; Mandel et al., 1992; Bowman et al., 1993) and CAULI FLOWER (Bowman et al., 1993). LEAFY and APETALAI have been cloned, and their RNA is present in nascent and developing floral primordia (Weigel et al., 1992; Mandel et al., 1992).

Less is known about the other process, namely how the apical meristem structure is established and maintained. In classical botany, the apical meristem is divided into two regions, a central zone $(\mathrm{CZ})$ and a peripheral zone (PZ) (Vaughn, 1952; Vaughn and Jones, 1953; Brown et al., 1964). Under this model, organ primordium initiation occurs in the PZ, while the CZ consists of slowly dividing cells that replenish the PZ. The apical meristem is further organized into three cell layers that in general remain clonally distinct throughout development (Satina et al., 1940; Miksche and Brown, 1965). The study of fasciation, where the meristem grows abnormally as a band- or ringlike structure, has fascinated naturalists for centuries (Linneaus, 1751; Moquin-Tandon, 1840; Masters, 1869; White, 1916, 1948; Gorter, 1965). Fasciated plants have even been the object of worship (Tadulingam and Jacob, 1925). Fasciation has often been found to be due to a single, recessive trait. Examples of this have been found in pea (Mendel, 1866), Celosia cristata (White, 1948), tobacco (White, 1916), tomato (Young and MacArthur, 1947; Mertens and Burdick, 1954; Szymkowiak and Sussex, 1992) Zea mays (Emerson, 1911) and soybean (Takagi, 1929). More recently, Leyser and Furner (1992) have shown that Arabidopsis plants with mutations in CLAVATAl (CLVI), FASCIATA1 or FASCIATA2 can exhibit disrupted phyllotaxy, inflorescence fasciation, and altered leaf development. They further demonstrated that 5 day old $c l v 1$ apical meristems are taller and wider than wild type, while 5 day old fas 1 apical meristems are wider but shorter than wild type. A preliminary investigation has identified three mutations, fey, dip and shz, that affect apical meristem structure (Medford et al., 1992), but these mutations can also disrupt cotyledon and leaf development, and cause meristem necrosis, so these genes may not be specific to meristem development. Medford et al. (1992) also presented an initial analysis of $f u f$, a mutation that causes inflorescence fasciation, and demonstrated that the fuf apical meristem is enlarged at 7 days old compared to wild type. 
The same two processes mentioned above as necessary for apical meristem development are also involved in flower development: the establishment of floral meristem structure, and the determination of floral organ identity. Our understanding of floral organ specification has been advanced by the characterization and cloning of the homeotic gene loci AGAMOUS, APETALA3 and PISTILLATA (Bowman et al., 1991; Yanofsky et al., 1990; Drews et al., 1991; Jack et al., 1992; K. Goto and E. M. M., unpublished data), and the characterization of APETALA2 (Bowman et al., 1991). Very little is known, on the other hand, about how floral organ number and position are determined. Smyth et al. (1990) described wild-type organogenesis in developing Arabidop sis flowers. Flowers initially arise as undifferentiated bulges on the flanks of the apical meristem and soon give rise to four sepal primordia establishing the first whorl (stage 3 all stages according to Smyth et al., 1990). After the sepals grow to overlie the floral primordium (stage 4), four petal and six stamen primordia arise (stage 5), and soon after, carpel primordia (stage 6) initiate in the center of the floral meristem. Each distinct organ type occupies a separate whorl, with sepals in the first whorl, petals in the second whorl, stamens in the third whorl, and carpels in the fourth whorl. Leyser and Furner (1992) described three clvl alleles that exhibited a variable number of extra organs in each whorl.

Here we present a morphological and genetic analysis of a series of mutations in the Arabidopsis CLAVATAl locus. Our investigations have revealed that $c l v l$ disrupts the apical meristem structure by enlarging it in weak alleles, causing fasciation in intermediate alleles and causing massive overproliferation in the strongest allele. We have also observed increases in the size of clvl floral primordia at the earliest stages of organ initiation, and that the degree of increase in floral meristem size correlates with the increase in floral organ number in the mutant alleles. We report here that clv1 further disrupts the floral meristem structure by developing additional whorls of carpels inside of the gynoecium generated by the fourth-whorl carpels. Genetic interactions between $\operatorname{clv} 1$ mutations and mutations of six other genes have been investigated. We observe additive phenotypes for $c l v 1$ double mutants with ap 2, ap3, pi and $a g$, indicating clv 1 affects the underlying floral meristem structure upon which floral homeotic genes act. We demonstrate that $c l v 1$ further affects floral meristem structure by altering patterns of AGAMOUS and APETALAI expression compared to wild type. Mutant combinations with apl result in the transformation of the center of the flower into meristem tissue, and mutant combinations with lfy result in almost complete transformation of the flowers into shoot structures, indicating that CLV1 plays a hitherto unsuspected role in floral meristem identity. We discuss models for the generation of fasciation and possible mechanisms of action for CLVI in Arabidopsis development.

\section{MATERIALS AND METHODS}

For all plants, seeds were sown on a thin covering $(5-10 \mathrm{~mm})$ of Redi-earth peat-lite mix over a 1:1:1 mixture of perlite:vermiculite:soil. After 4 days at $4^{\circ} \mathrm{C}$, plants were placed under lights. All plants, except $a g-2$ and clv1-1 ag-2, were grown under $600 \mathrm{ft}-$ candles of constant cool white fluorescent light at $23-25^{\circ} \mathrm{C}$. Plants were fertilized at about 10 days after germination. ag-2 flowers grown under the above conditions often lack sepals in the inner whorls (whorls 4, 7, 10, etc.), making organ counts as in Table 3 difficult. Therefore, $a g-2$ and $c l v 1-1 a g-2$ plants were grown in a Percival chamber under constant $225 \mathrm{ft}$-candles of cool white fluorescent at $25^{\circ} \mathrm{C}$. These conditions are identical to those in Bowman et al., 1989, 1991. Short day conditions were also carried out in a Percival chamber. Plants were subjected to a 10 hour light/ 14 hour dark cycle under $325 \mathrm{ft}$-candles of cool white fluorescent light at $24^{\circ} \mathrm{C}$. Various $c l v 1$ phenotypes, especially fasciation, are sensitive to general growing conditions and crowding in particular. Thus seeds were sown at a maximum density of 1 seed per 4 $\mathrm{cm}^{2}$.

clv1-1 is an ethyl methanesulfonate (EMS)-induced allele originally isolated in ecotype Landsberg by Koornneef et al. (1983) (see Table 1). clv1-4 is an X-ray induced allele isolated in either Estland or Limburg ecotype by McKelvie (1962). For double mutant combination with lfy-1 (Fig. 12) and for SEM analysis in Fig. 1D-F, clv1-4 was first backcrossed to ecotype Columbia. For all other analyses, $c l v 1-4$ was backcrossed to ecotype Landsberg erecta three times. clv1-5 appeared spontaneously in plants of Landsberg erecta background. clv1-5 was backcrossed to ecotype Landsberg erecta twice.

A specific screen was performed to isolate additional clvl alleles. To do so, $c l v 1-1$ pi-1 double mutant plants in Landsberg were hand pollinated with ecotype Columbia pollen that had been subjected to 7500 rads of X-rays. The 15,000 seeds that developed were grown and screened for phenotypically clv1 plants. 5 phenotypically clv1 plants were identified, and seeds from these selfed $\mathrm{M}_{1}$ plants were grown to verify that no wild-type plants segregated out. Seed was collected from individual $\mathrm{M}_{2}$ plants, and DNA was isolated from pools of $\mathrm{M}_{3}$ plants, each pool representing a single $\mathrm{M}_{2}$ plant. For each new clv1 allele, $\mathrm{M}_{3}$ DNA from $15-20 \mathrm{M}_{2}$ individuals was analyzed by Southern hybridization for restriction fragment length polymorphism (RFLPs). Cosmids N7-24, KG-24 and 532 map in the region of $c l v 1$ (S. E. C., R. W. Williams and E. M. M., unpublished data), and were used as probes. For three of the new alleles, all $\mathrm{M}_{2}$ plants were homozygous for Landsbergspecific RFLPs, indicating that the X-ray induced allele had been lost. This is possibly the result of a large deletion (perhaps a chromosome arm) that is unable to transmit through gametes. For two of the new alleles, Landsberg- and Columbia-specific RFLPs were found in an approximately 1:1 ratio, indicating that the new allele had transmitted to the next generation. For each of these new alleles (clv1-6 and clv1-7), an $\mathrm{M}_{2}$ plant homozygous for Columbiaspecific RFLP was chosen and an $\mathrm{M}_{3}$ offspring from it was back crossed to Landsberg erecta before analysis.

Scanning electron microscopy (SEM) was performed as described (Bowman et al., 1989).

In situ hybridizations were carried out according to Drews et al. (1991), using synthesized $A G$ probe as described. $A P 1$ probe was synthesized from the pAM128 plasmid kindly supplied by A. Mandel and M. Yanofsky (Mandel et al., 1992).

For confocal laser scanning microscopy (CLSM) of flowers, the following protocol was developed. Inflorescence tissue was fixed for 4 days in a solution of 10:5:70 formalin:propionic acid:ethanol. The tissue was taken through an ethanol series to $100 \%$ ethanol and left in $100 \%$ ethanol overnight to eliminate chlorophyll. The tissue was then rehydrated and stained for 6 days in $0.1 \mathrm{M} \mathrm{L}$ arginine, $\mathrm{pH} 12.4$, with $5 \mathrm{mg} / \mathrm{ml}$ propidium iodide, and destained for 4 days in $0.1 \mathrm{M}$ L-arginine, $\mathrm{pH}$ 8. After ethanol and xylene series, the tissue was cleared for several hours in $100 \%$ xylene. All series were performed gradually, using several steps each with small changes in ethanol and/or xylene concentration. The tissue was dissected and mounted in immersion oil, and viewed with an 
argon laser (488 and $514 \mathrm{~nm}$ excitation wavelength) using the Zeiss confocal LSM 10 microscope. Images were cropped and the brightness and contrast were adjusted using Adobe Photoshop 2.0 for Macintosh computers, and printed using a Nikon printer at $200 \mathrm{dpi}$ resolution.

\section{RESULTS}

\section{clavata1 alleles}

We have investigated five clvl alleles as listed in Table 1. clv1-1 is the original clv1 allele isolated by Koornneef et al. (1983). clv1-4 was isolated by McKelvie (1962). clv1-5 was a spontaneous mutation isolated in this lab. clv1-6 and $c l v 1$ 7 were isolated in a pollen mutagenesis screen designed to identify new clvl alleles (see Materials and methods).

\section{clavata1 mutants have abnormal apical meristems}

It is clear from superficial examination that clavatal (clvl) mutants exhibit defects in the inflorescence meristem (IM). First, the primary IM is usually fasciated in the stronger alleles $c l v 1-4$ and $c l v 1-1$. These fasciated meristems grow as a strap-like structure (Leyser and Furner, 1992). Additionally, the normal spiral phyllotaxis of emerging flowers (Smyth et al., 1990) is disrupted, suggesting that some aspect of floral primordium initiation on the flanks of the apical meristem is affected.

To determine the nature of these defects in greater detail, inflorescence meristems were fixed and examined by scanning electron microscopy (SEM). clv1-5 plants exhibited disrupted phyllotaxy, but were only rarely fasciated. As shown in Fig. 1A,B, the apical meristem of clv1-5 plants was enlarged in width and height compared to that of wild-type plants. The clv1-5 apical meristem had a larger number of young floral primordia at its flanks, and these floral primordia did not appear to be spirally arranged. clv1-1 and clv1-4 apical meristems, on the other hand, developed as fasciated meristems when grown at $25^{\circ} \mathrm{C}$. These fasciated meristems grew as a line instead of a point, with floral primordia developing along the sides of the apical meristem line (Fig. 1C-F). An even more dramatic defect in inflorescence meristem structure could be observed when clv1-4 plants were grown at $16^{\circ} \mathrm{C}$. The clvl-4 meristem, instead of becoming fasciated, developed into a huge misshapen mass that dwarfed the apical meristem of wildtype plants grown at $16^{\circ} \mathrm{C}(\mathrm{Fig} .1 \mathrm{G}, \mathrm{H})$. Despite this disruption in the apical meristem, floral primordia were still generated at its base.

Table 1. clavata1 alleles

\begin{tabular}{lll}
\hline Allele & Mutagen & \multicolumn{1}{c}{ Source } \\
\hline $\operatorname{clv} 1-1$ & EMS & Koornneef (1983) \\
$\operatorname{clv1-4}$ & X-ray & McKelvie (1962) \\
$\operatorname{clv} 1-5$ & unknown & This paper \\
$\operatorname{clv} 1-6$ & X-ray & This paper \\
$\operatorname{clv} 1-7$ & X-ray & This paper
\end{tabular}

clavata1 alleles analyzed in this study are listed. See Materials and methods for description of $c l v 1-5, c l v 1-6$ and $c l v 1-7$ isolation. EMS, ethyl methanesulfonate.
To determine how a fasciated meristem is generated, $c l v 1$ 5, clv1-1, clv1-4 and wild-type plants grown at $25^{\circ} \mathrm{C}$ were examined at day 8 through day 13 of development (with day 1 being 24 hours after removal from cold shock, see Materials and methods). By day 7, the wild-type vegetative meristem has generated 5 leaf primordia (Medford et al., 1992). In our growth conditions, the period from day 8 through 13 includes the development of the last rosette leaves, the cauline leaves and the initial flower primordia, and thus includes the transition to flowering. As Fig. 2 shows, the apical meristem of $c l v 1$ plants was both wider and taller than wild-type plants at day 8 , with the increase in $c l v 1$ meristem size depending on the severity of the allele. The $c l v 1-1$ meristem continued to grow larger until about 11-12 days, during the transition from vegetative to floral growth, when the clv1-1 apical meristem extended out in one or both directions, leading to fasciation (Fig. 2K,O). These extensions occurred at the shoulders of the apical meristem at the approximate locations where leaf and flower primordia are generated. The prominence of the original apical meristem was sometimes retained (Fig. 1E) and sometimes lost (data not shown) as flowering progressed. clv1-5 apical meristems, on the other hand, retained their radial symmetry, and thus rarely became fasciated (Fig. $2 \mathrm{~J}, \mathrm{~N})$. clv1-4 exhibited the greatest increase in apical meristem size as compared to wild type, forming apical meristem structures with a variety of shapes (Fig. 2).

Because the transition to flowering and the initial occurrence of fasciation coincide during development, we sought to determine if the transition to flowering was necessary for fasciation. Wild-type, $c l v 1-1$, and $c l v 1-4$ plants were grown under short day conditions (10 hours light/14 hours dark), in which the transition to flowering is delayed, and, as a result, the vegetative growth phase is extended. Unexpectedly, clv1-4 plants were not affected by the short day light regime and bolted after as few as 26 days. Wild-type and clv1-1 plants, on the other hand, did not bolt until 55 and 60 days, respectively. Fig. 3 shows apical meristems from these plants at 31 days. The $c l v 1-1$ and wild-type meristems were still generating leaves (Fig. 3A,B), while the clv1-4 plant had a well-developed inflorescence meristem with mature flowers (Fig. 3C). Despite the fact that $c l v 1-1$ plants had not undergone a transition to flowering, the apical meristems of these plants were clearly fasciated, indicating that the floral transition is not necessary for fasciation.

\section{clavata1 mutants have increased floral organ number}

Plants mutant for $c l v l$ were initially identified as having an increase in carpel number (Koornneef et al., 1983), but subsequent analysis revealed that the mutation causes an increase in the number of all floral organ types (Leyser and Furner, 1992). We analyzed five $c l v 1$ alleles for the number of organs in each whorl (see Table 1 and Materials and methods for origin of alleles). Fig. 4 shows a flower from a weak (clv1-6, Fig. 4B) and strong (clv1-4, Fig. 4C) allele in comparison with a wild-type flower (Fig. 4A). Fig. 5 shows mean floral organ numbers for each mutant allele. clv1-4 plants exhibited the greatest increase in organ number. The severity of the phenotype of other $c l v 1$ alleles was in decreasing order: $\operatorname{clv} 1-1>\operatorname{clv} 1-5>\operatorname{clv} 1-6>\operatorname{clv} 1-7$. 

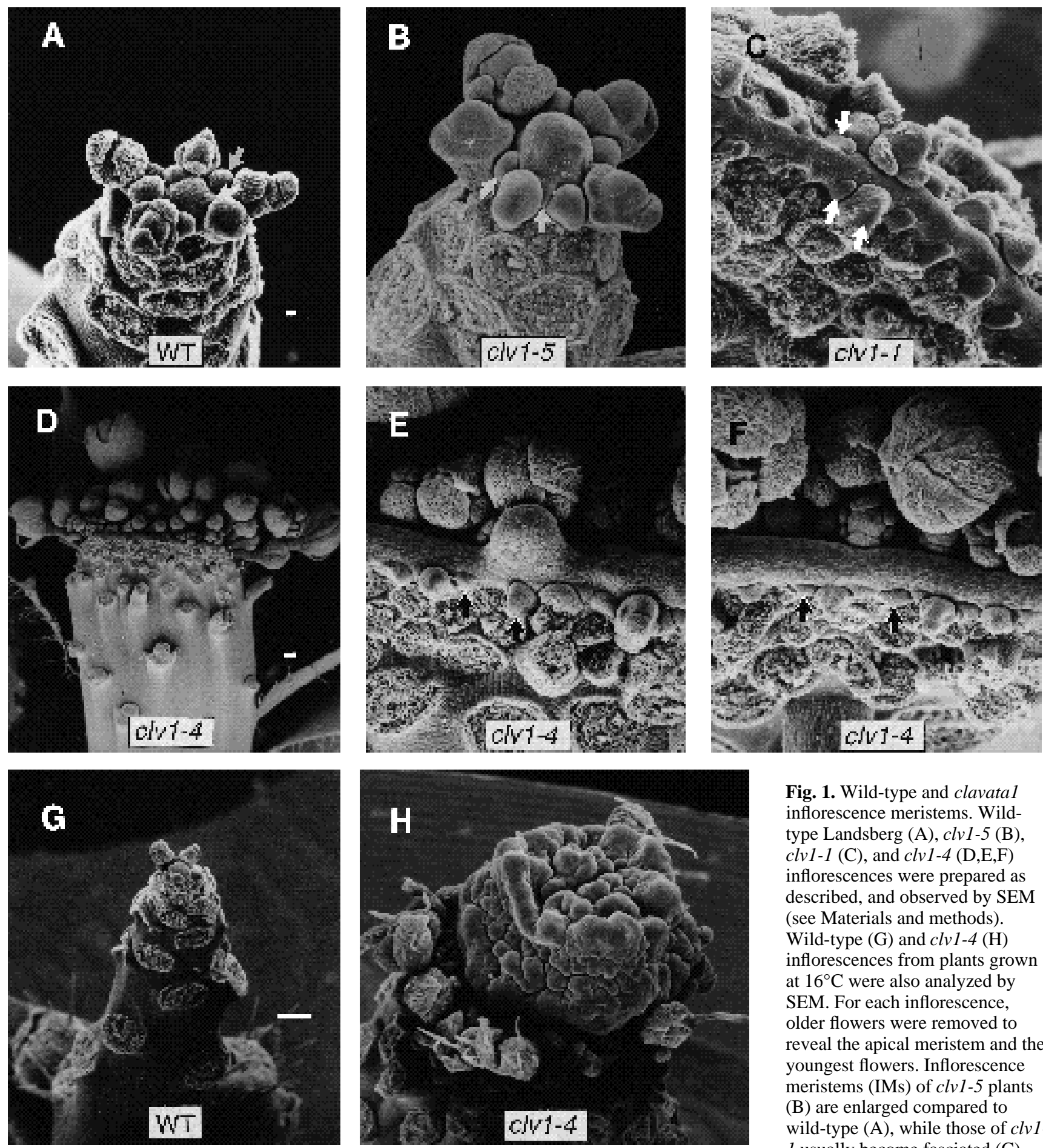

Fig. 1. Wild-type and clavatal inflorescence meristems. Wildtype Landsberg (A), $c l v 1-5$ (B), clv1-1 (C), and clv1-4 (D,E,F) inflorescences were prepared as described, and observed by SEM (see Materials and methods). Wild-type (G) and clv1-4 (H) inflorescences from plants grown at $16^{\circ} \mathrm{C}$ were also analyzed by SEM. For each inflorescence, older flowers were removed to reveal the apical meristem and the youngest flowers. Inflorescence meristems (IMs) of clv1-5 plants (B) are enlarged compared to wild-type (A), while those of $c l v 1$ 1 usually become fasciated (C).

clv1-4 IMs fasciate in an ER background (D - closer view in E and F), and often the original apical meristem is still distinct (E). Note parallel rows of cells on the fasciated meristem in (F). When grown at $16^{\circ} \mathrm{C}, c l v 1-4 \mathrm{er}$ IMs $(\mathrm{H})$ become massively proliferative and dwarf wild-type IMs grown at $16^{\circ} \mathrm{C}(\mathrm{G})$. Floral primordia are indicated with arrows. Bars, $10 \mu \mathrm{m}(\mathrm{A})$ and $100 \mu \mathrm{m}(\mathrm{D}, \mathrm{G})$. Note A-C,E and F are shown at identical magnification, as are $\mathrm{G}$ and $\mathrm{H}$. All plants except D,E and F carried the erecta mutation.

Except for the weakest alleles, $\operatorname{clv} 1-6$ and $\operatorname{clv} 1-7$, the mean numbers of organs in all four whorls were increased in homozygous mutant plants. Organ numbers in the inner two whorls (carpels and stamens) were more affected than organ numbers in the outer two whorls (sepals and petals) in all alleles. clv1-4 and $c l v 1-1$ also showed a semi-dominant phenotype. The early flowers that developed on $c l v 1-1 /+$ and $c l v 1-4 /+$ plants had extra fourth-whorl carpels, but they did not have a detectable fifth whorl (data not shown), as do homozygous clvl flowers (see below). No other 

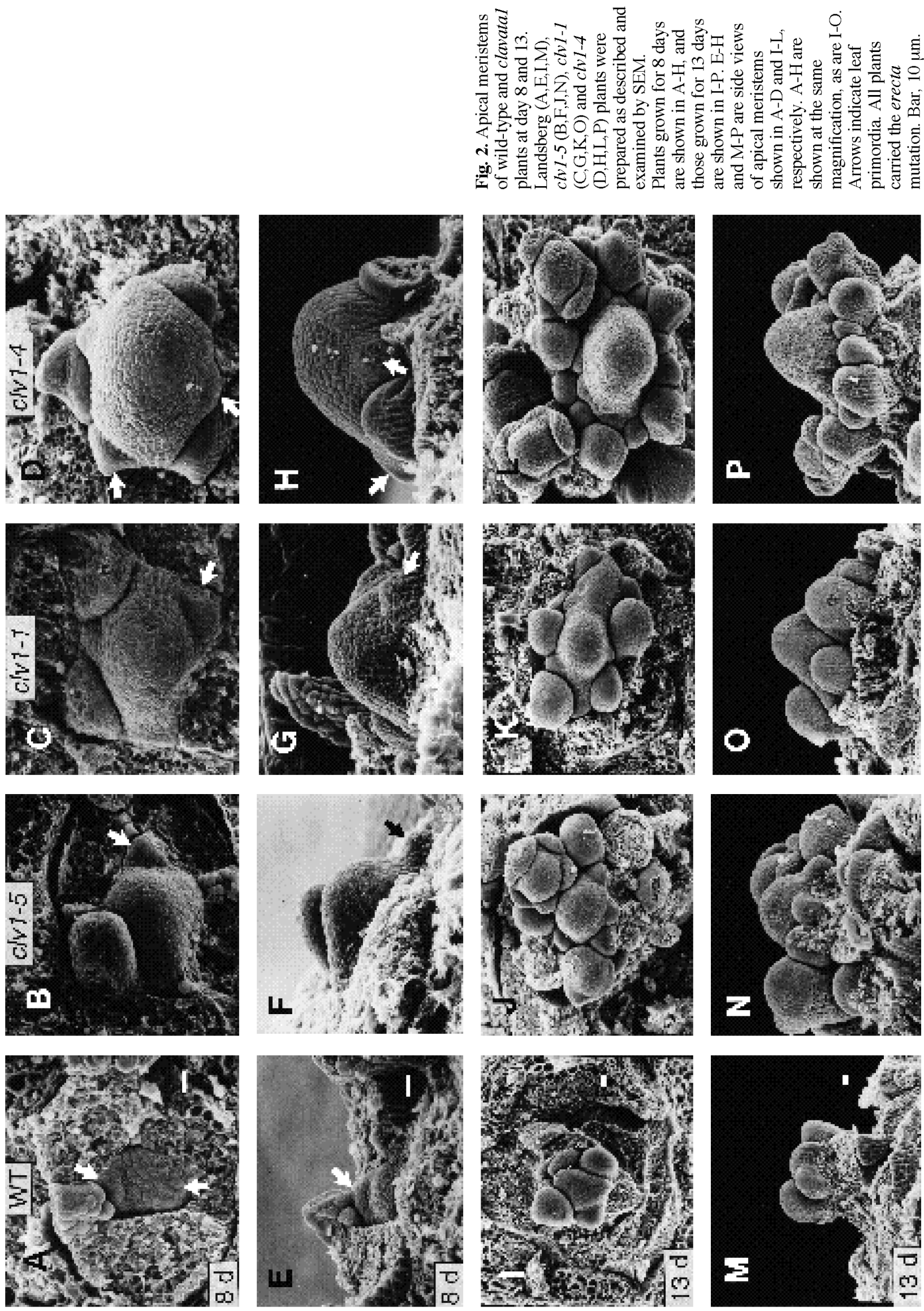

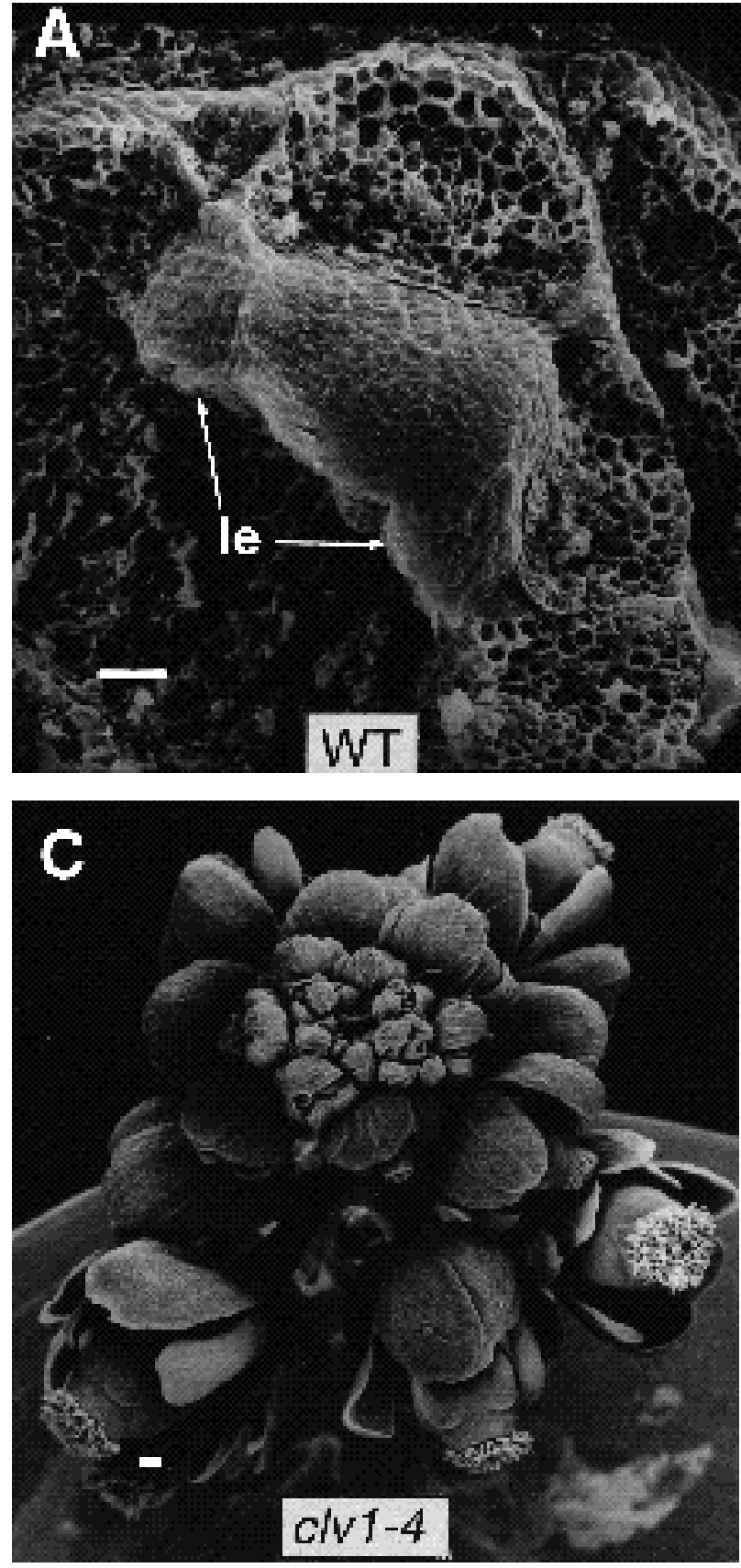

consistent defects were observed in $c l v 1-1 /+$ and $c l v 1-4 /+$ plants.

\section{clavata1 mutants have increased floral meristem size and whorl number}

To determine the effect of $c l v 1$ mutations on early stages of flower development, wild-type and $c l v 1-1$ flowers were analyzed by confocal laser scanning microscopy (CLSM). CLSM has the advantage over conventional sectioning techniques in that it can be used to rapidly take sections through whole-mount tissue by optically filtering background fluorescence above and below the plane of focus. Its use in plants had been limited to studies of autofluorescent tissue such as pollen grains and ovules, presumably because of the difficulty that the cuticle and cell wall present to the staining

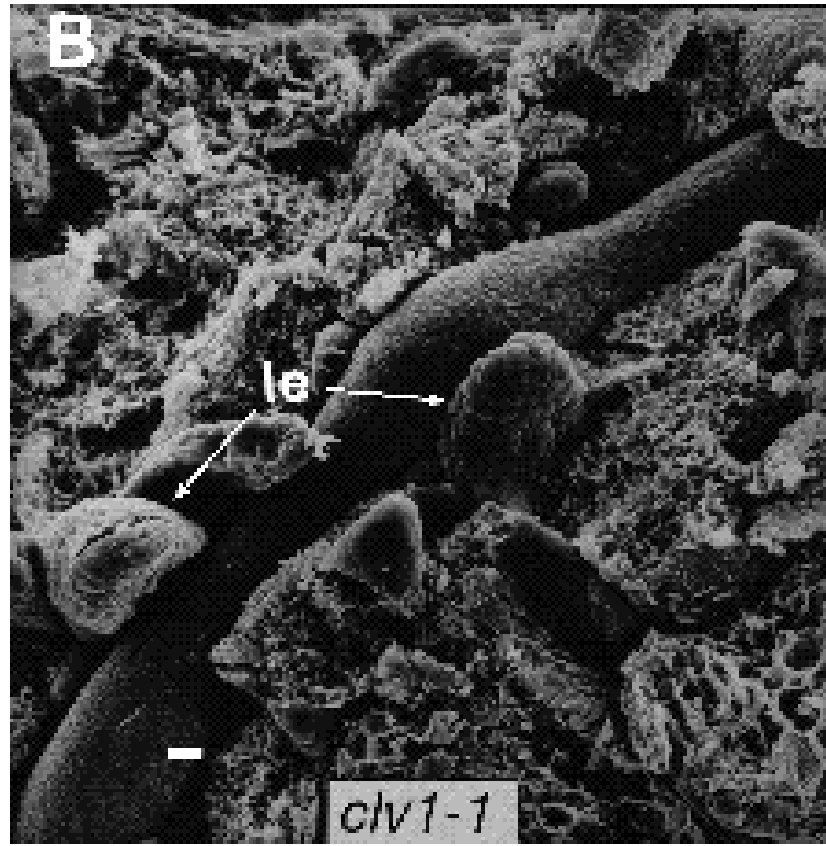

Fig. 3. Wild-type and clavatal meristems in plants grown under short day conditions. Wild-type Landsberg (A), $c l v 1-1$ (B), and clv1-4 (C) plants were grown under a 10 hour light / 14 hour dark regime. Plants were collected 31 days after germination and prepared for SEM. For A and B, leaves were dissected to reveal the vegetative meristem. Note that the $c l v 1$ 4 plant (C) was unaffected by short day conditions and bolted much earlier than the others, resulting in a inflorescence meristem at 31 days. The $c l v 1-1$ apical meristem, on the other hand, became fasciated (B), despite the fact that it had not yet undergone the transition to flowering. le, leaf primordia. Bars, $10 \mu \mathrm{m}(\mathrm{A}, \mathrm{B})$ and $100 \mu \mathrm{m}(\mathrm{C})$. All plants carried the erecta mutation.

of whole-mount plant tissue. We have developed a protocol for fixing and clearing plant tissue that has been stained with propidium iodide, a nuclear stain, which allows CLSM analysis (see Materials and methods). As shown in Fig. 6, optical sections through stage 3 flowers (all stages according to Smyth et al., 1990) revealed that clv1 floral meristems were taller than wild-type meristems (Fig. 6A-C). The floral meristem size from the inner base of the sepal primordia to the top of the flower was measured for CLSM sections and paraffin sections of stage 3 wild-type $c l v 1-1$ and $c l v 1-4$ flowers (Table 2). The mean floral meristem height of 12 $\mu \mathrm{m}$ in wild-type flowers was dramatically increased to 23 $\mu \mathrm{m}$ in clv1-1 flowers and $41 \mu \mathrm{m}$ in clvl-4 flowers. There was a less dramatic increase in the width of $c l v 1$ stage 3 flowers. The mean width of the floral primordia between the 

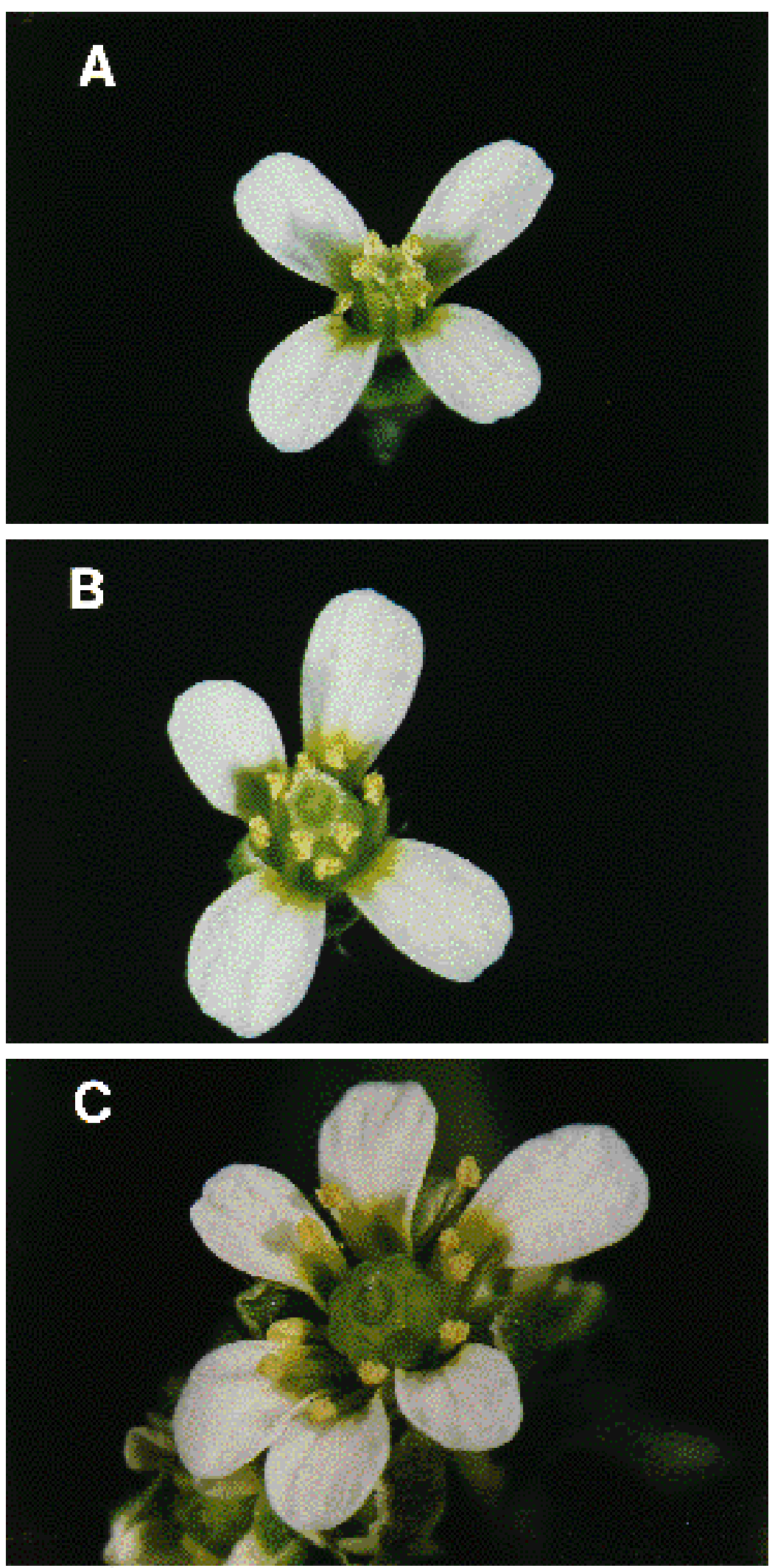

Fig. 4. Wild-type and clavatal flowers. Shown are photos of wild-type Landsberg (A), a weak clavatal allele, clv1-6 (B), and a strong clavatal allele, $\operatorname{clv} 1-4(\mathrm{C})$. All plants carried the erecta mutation. inner bases of the sepal primordia were $49 \mu \mathrm{m}$ for wild type, $55 \mu \mathrm{m}$ for $c l v 1-1$ and $66 \mu \mathrm{m}$ for clvl-4.

To determine if this increase in floral meristem size in clvl flowers was due to more or larger cells, nuclei were counted in the CLSM sections shown in Fig. 6. The wildtype flower contained 21 nuclei in the region measured above, while the clv1-1 flower contained 61 nuclei and the clv1-4 flower contained 73 nuclei. 


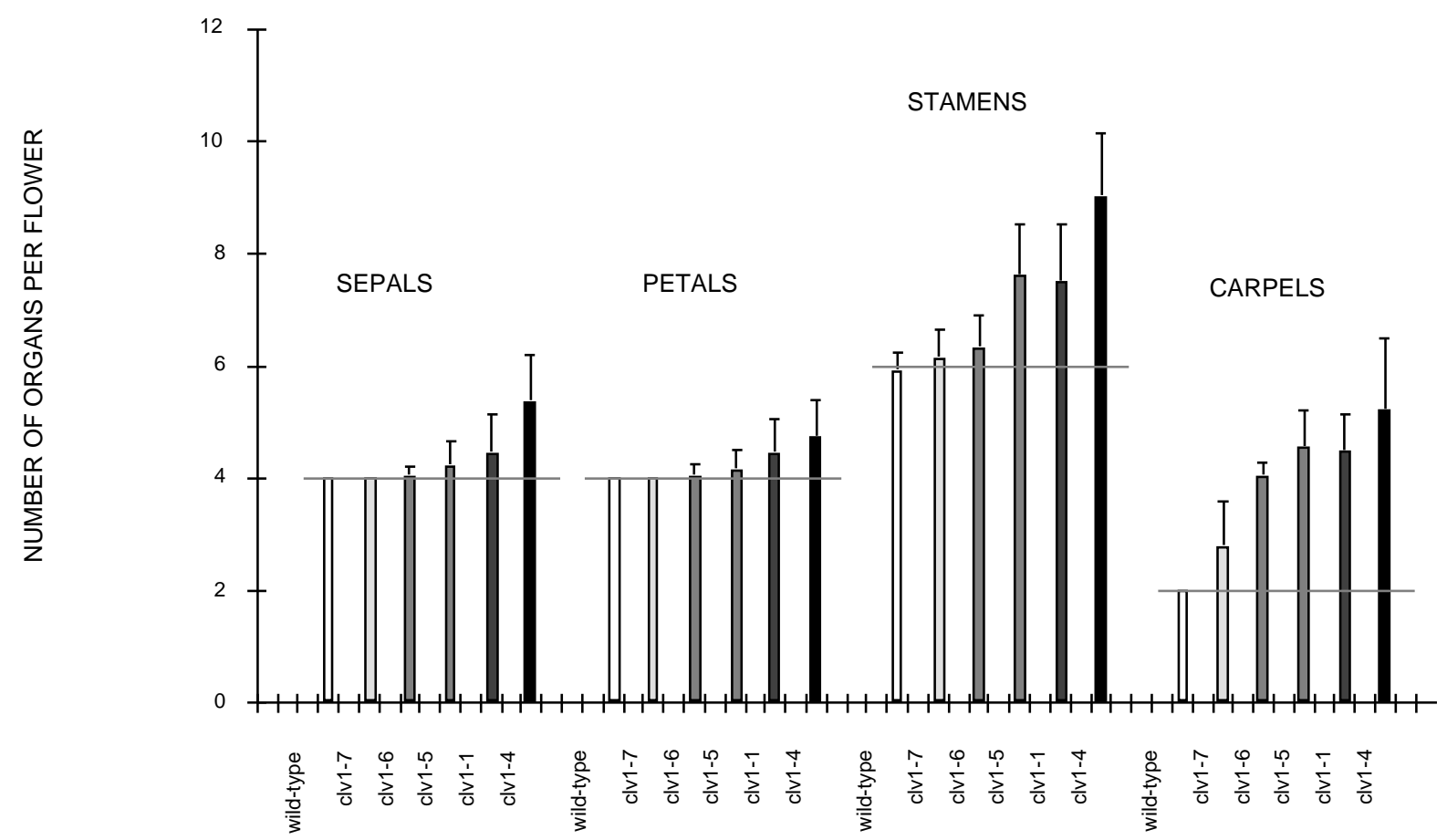

Fig. 5. The number of organs in wild-type and clavatal flowers. Bars represent the mean number of indicated organs for flowers of wildtype Landsberg, $\operatorname{clv1-7,} c l v 1-6, \operatorname{clv} 1-5, \operatorname{clv} 1-1$ and $c l v 1-4$ plants. At least 90 flowers were counted for each mean calculated. Only the first ten flowers on any given plant were analyzed. Standard errors are indicated by vertical black lines. The dotted horizontal lines represent the normal wild-type organ number. clv $1-5$ stamens include 0.39 antherless filaments per flower. $c l v 1-1$ stamens include 0.32 antherless filaments per flower. $\operatorname{clv} 1-4$ stamens include 0.52 antherless filaments per flower. Note that the upper limit of the mean plus standard error for the number of stamens for wild-type flowers exceeds six due to flowers with 4 and 5 stamens, but no wild-type flowers were observed with more than six stamens. All plants carried the erecta mutation.

Table 2. Floral meristem sizes at stage 3

\begin{tabular}{lccc}
\hline Genotype & Width $(\mu \mathrm{m})$ & Height $(\mu \mathrm{m})$ & $n$ \\
\hline WT & $49 \pm 6$ & $12 \pm 3$ & 23 \\
clv1-1 & $55 \pm 5$ & $23 \pm 6$ & 21 \\
clv1-4 & $66 \pm 9$ & $41 \pm 7$ & 13
\end{tabular}

Confocal laser scanning microscopy sections (see Materials and methods) and $6 \mu \mathrm{m}$ paraffin sections of Landsberg, $c l v 1-1$ and $c l v 1-4$ stage 3 flowers were measured. Width measurements were taken between the base of the sepal primordia. Height measurements were taken from the inner base of the sepal primordia to the top of the flower. The mean width and height of wild-type, $\operatorname{clv} 1-1$ and $c l v 1-4$ flowers are presented and the standard error for each mean is indicated. The number of flowers measured for each mean is listed under $n$. All plants carried the erecta mutation.

At stage 6 in wild-type flowers, carpel primordia arose at the center of the floral meristem, at which time the floral meristem terminates (Fig. 6D), while in clv $1-1$ flowers the fourth-whorl carpels arose on the flanks of a central dome (Fig. 6E). Optical sections of clv1-4 flowers showed that this central dome was enlarged compared to $c l v 1-1$ flowers (Fig. $6 \mathrm{~F})$. SEM of stage $6 c l v 1-1$ and $c l v 1-4$ flowers also indicated that the carpels arose as a ring of organs around a still-proliferating central dome, with the dome in clv1-4 flowers being larger (Fig. 6G-I). We define this central dome as a fifth whorl.

To determine the fate of this fifth whorl, clv1-1 gynoecia were examined late in development after the outer organs had senesced and as seeds were developing (stage 17). After removing the outer silique coat, we observed an additional gynoecium inside of the gynoecium generated by the fourthwhorl carpels (Fig. 7A). This inner gynoecium was found in every $c l v l-1$ silique in over 100 flowers analyzed. In weaker alleles, this inner gynoecium was much reduced in size (Fig. 7B), while in the strongest allele, clv1-4, the growth of this inner gynoecium was dramatically increased. In a typical clv1-4 gynoecium, as shown in Fig. 7C, a 'sixth whorl' gynoecium was observed inside of the fifth-whorl gynoecium, with what appeared to be meristem tissue emerging out of this sixth whorl gynoecium (Fig 7D, cf. Figs $1 \mathrm{H}, 9 \mathrm{H}, 12 \mathrm{G}$ and 14B). In rare cases, a new inflorescence with developing flowers emerged from the gynoecium in clv1-4 flowers (data not shown).

\section{Genetic combinations with other flower mutations}

Extensive genetic studies have examined the role of the homeotic loci APETALA2, APETALA3, PISTILLATA, and $A G A M O U S$ in establishing floral organ identity (Bowman et al., 1989; Meyerowitz et al., 1991; Bowman et al., 1991; Coen and Meyerowitz, 1991). Double mutant combinations of $\operatorname{clv} 1-1$ with the mutations apetala2-9, apetala3-1 and pis tillata-1 were all additive in phenotype (data not shown). The addition of the clvl-1 mutation resulted in extra organs of the type specified by the particular combinations of active homeotic genes (Bowman et al., 1989, 1991). As in clvl-1 

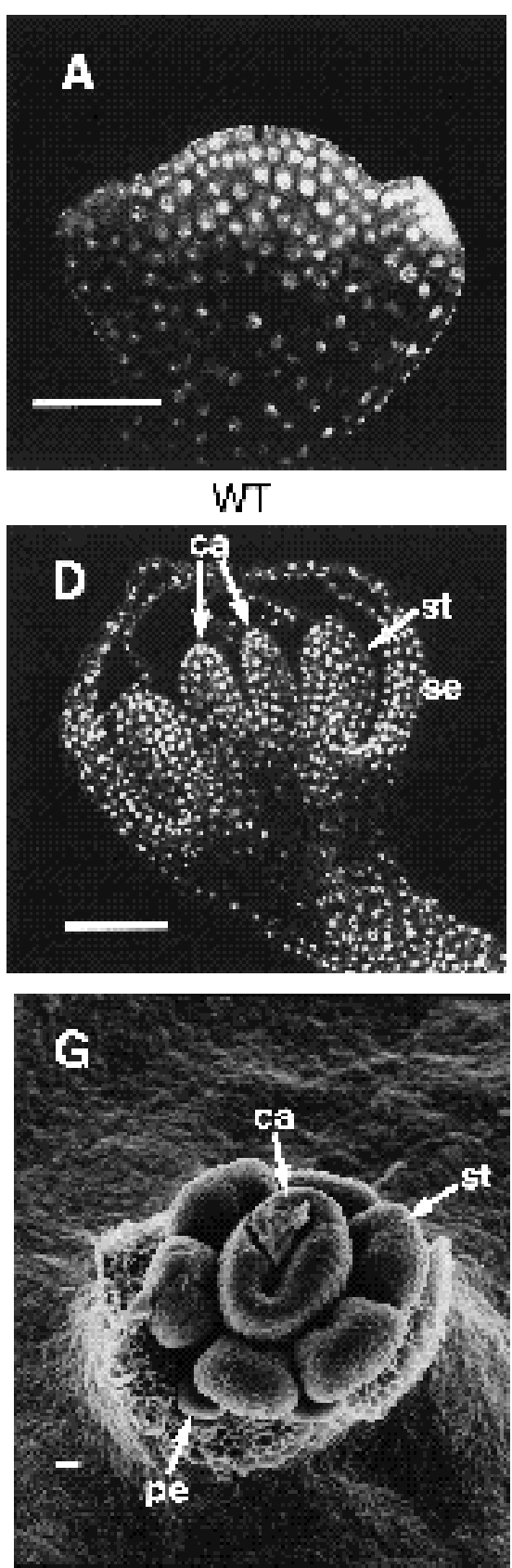

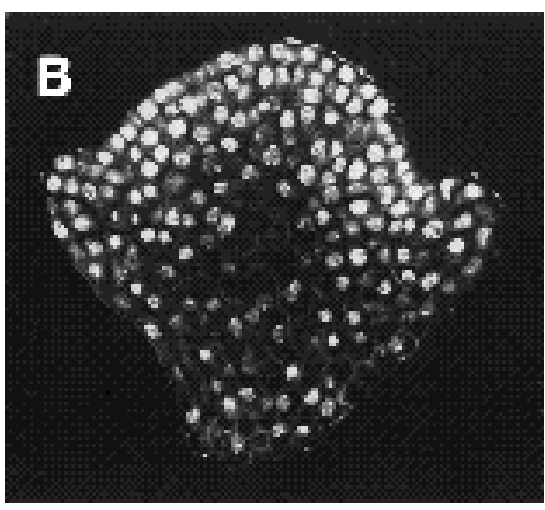

$c \mid v T-1$
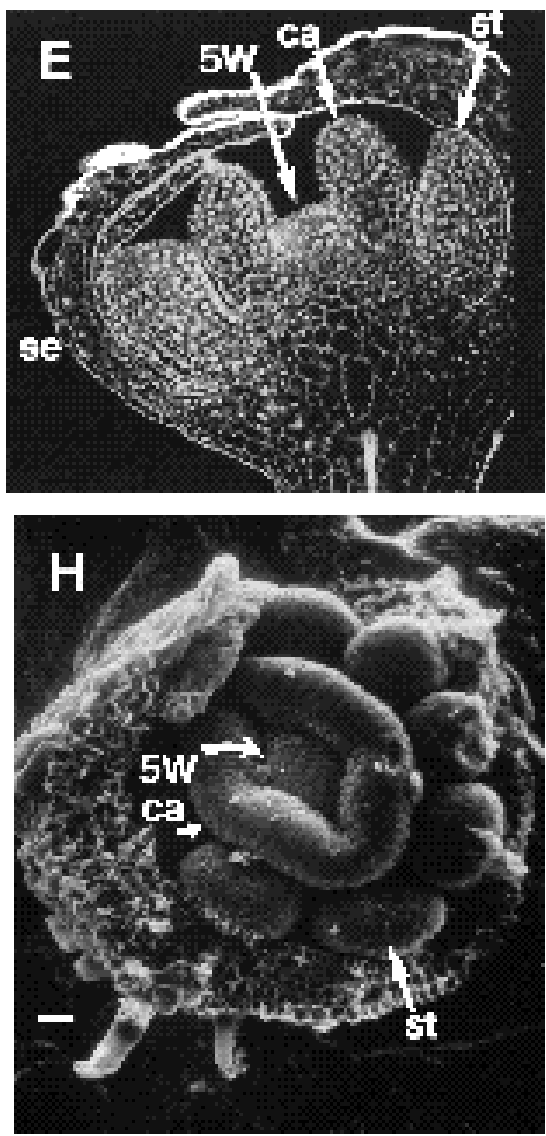

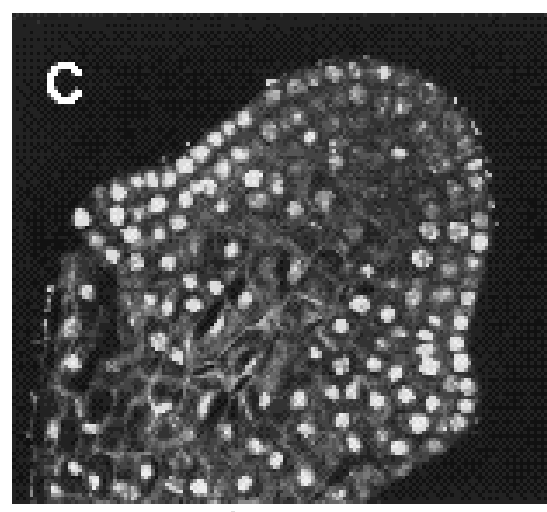

clvi-4
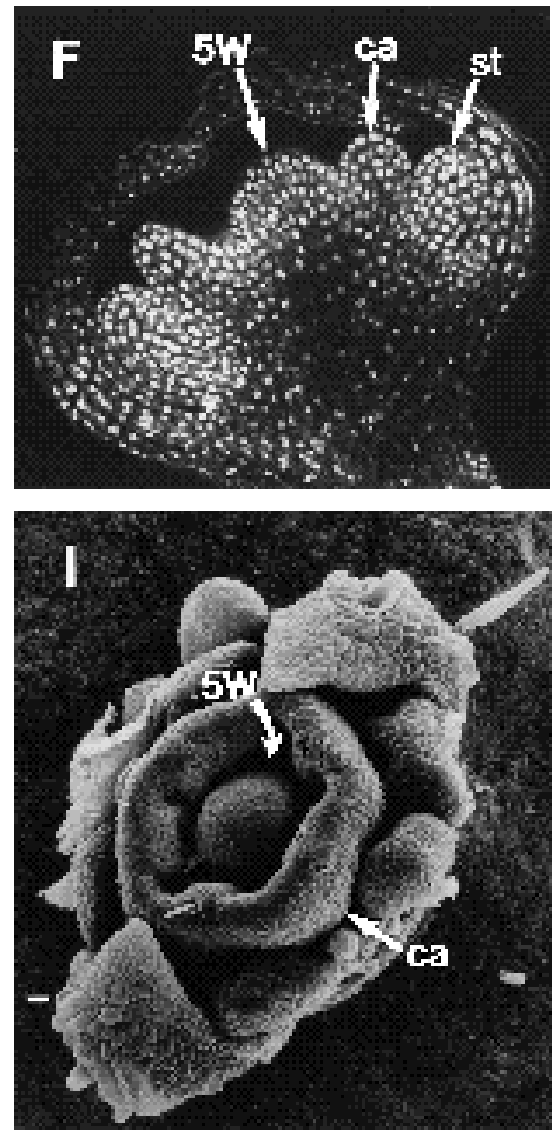

Fig. 6. Early development of wild-type and clavatal flowers. Wild-type Landsberg (A,D), $c l v 1-1$ (B,E), and clv1-4 (C,F) flowers were prepared for confocal laser scanning microscopy as described (see Materials and methods). (A-C) Optical sections were taken through stage 3 flowers. Note the taller floral meristem in $c l v 1-1$ (B) and $c l v 1-4$ (C) floral primordia. (D-F) Optical sections were taken through stage 6 flowers. Note that carpels in $c l v 1-1$ and $c l v 1-4$ flowers form on the flanks of the floral meristem instead of on the terminus as in wild type. Wild-type Landsberg (G), $\operatorname{clv} 1-1(\mathrm{H})$, and $c l v 1-4$ (I) flowers were prepared as described and observed by SEM after several sepals had been removed. Note the fifth whorl in $\operatorname{clv} 1-1$ and $\operatorname{clv} 1-4$ flowers. All plants carried the erecta mutation. se, sepal primordia; pe, petal primordia; st, stamen primordia; ca, carpel primordia; 5W, fifth whorl. Bars, $25 \mu \mathrm{m}$ (A), $50 \mu \mathrm{m}$ (D), $10 \mu \mathrm{m}$ (G-I). Note A,B and C are shown at the same magnification, as are D,E and F.

alone, the effects on organ number were weaker in the outer whorls and stronger in the inner whorls.

The AGAMOUS (AG) locus controls both the organ identity of stamens and carpels and the determinate growth of the flower, such that plants mutant in $A G$ produce flowers with an indeterminate (sepals, petals, petals)n phenotype
(Bowman et al., 1989). The phenotype of clv1-1 agamous2 doubly mutant plants was also essentially additive. As Table 3 shows, the number of organs in each whorl was increased in clv1-lag-2 flowers as compared to ag-2 single mutant flowers. Fig. 8 shows a comparison between ag-2 and clv1-1 ag-2 floral meristems. While the floral meristem 

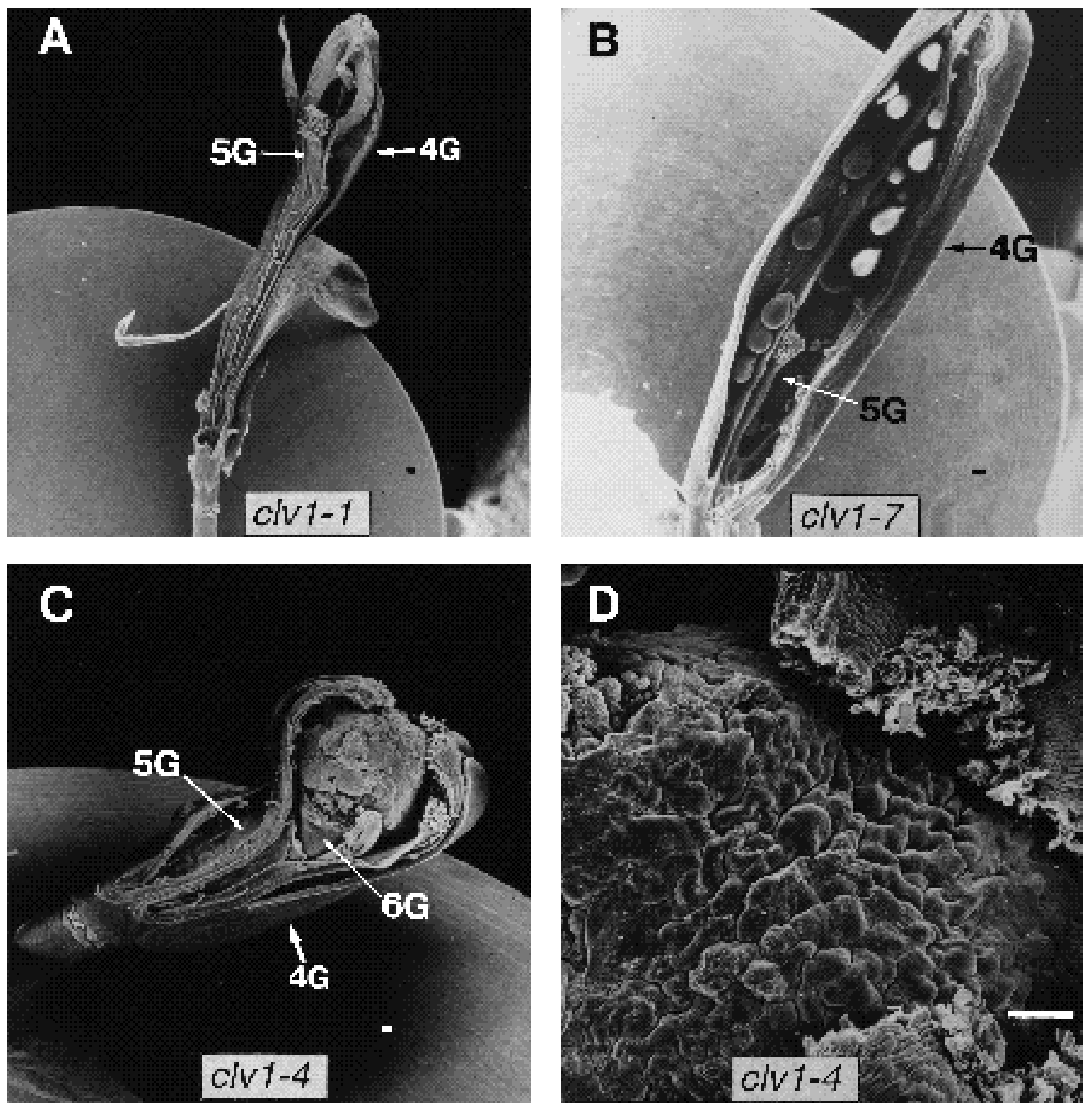

Fig. 7. The fate of the fifth whorl in $\operatorname{clv} 1$ flowers. $\operatorname{clv} 1-1$ (A), $\operatorname{clv1-7}(\mathrm{B})$, and $\operatorname{clv} 1-4$ (C,D) stage 17 gynoecia were prepared as described, and observed by SEM after the facing silique coat had been removed to reveal the inner gynoecium. The fifth-whorl gynoecium is reduced in size in $c l v 1-7$ (B), and greatly enlarged in $c l v 1-4$ (C). (D) A top view of the $c l v 1-4$ gynoecium in C. Note its similarity to meristem tissue in Figs 1H, 9H, 12G and 14B. 4G, gynoecium from fourth-whorl carpels; 5G, fifth-whorl gynoecium; 6G, sixth-whorl gynoecium. Bar, $100 \mu \mathrm{m}$. All plants carried the erecta mutation.

size was maintained throughout $a g-2$ flower development (Fig. 8A), clv1-1 ag-2 floral meristems became extremely fasciated (Fig. 8B-D).

The APETALAl (API) locus is involved in both floral organ identity and floral meristem identity (Irish and Sussex, 1990; Mandel et al., 1992; Bowman et al., 1993). apl-1 flowers consist of leaf-like sepals, few or no petals, and largely normal stamens and carpels (Fig. 9A,B). Also, additional flowers form in the axils of the leaf-like sepals (Irish and Sussex, 1990; Fig. 9B). clv1-1 apl-1 and clv1-4 apl-1 double mutant flowers displayed a surprising phenotype. Occasionally growing out of the center of the flower was a new inflorescence meristem (Fig. 9C,E,G). In clv1-1 ap1-1 flowers, the fourth-whorl gynoecium formed normally, and the new inflorescence grew through it (data not shown). Sections through developing clv1-1 apl-1 flowers indicated that the fifth whorl developed as an inflorescence meristem (data not shown). In clv1-4 apl-1 flowers with new inflorescences in the center of the flower, the fourth-whorl gynoecium usually did not form properly, and the carpels were often leaf-like, staminoid, or free standing (Fig. 9C,E). The frequency of new inflorescences in the center of $c l v 1-1$ ap1-1 and clv1-4 ap1-1 flowers was quite variable and higher in the early flowers. More common in clv1-4 apl-1 

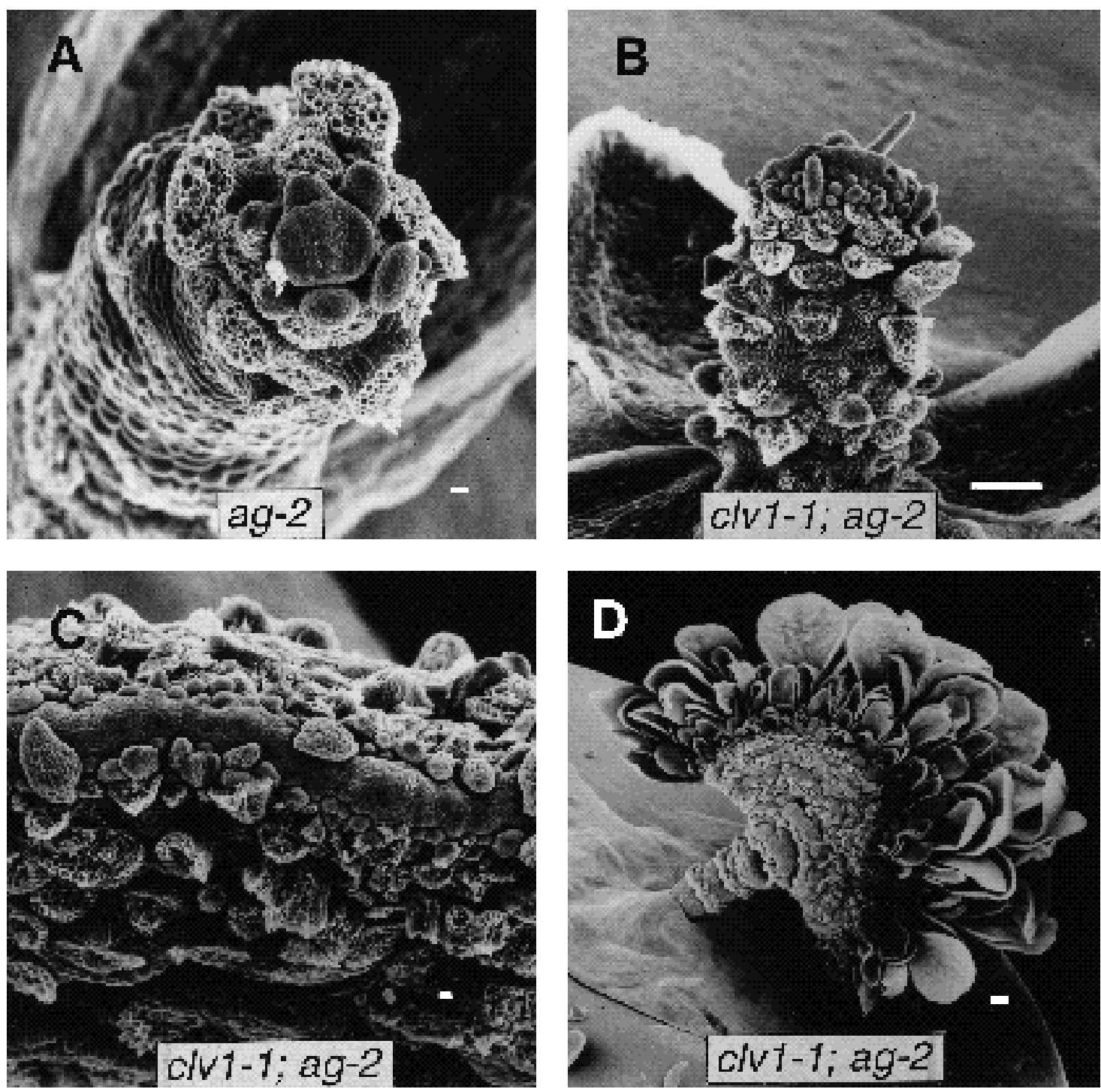

Fig. 8. agamous and clavatal agamous flowers. ag-2 (A) and clv1-1 ag-2 (B-D) mature flowers were prepared as described and observed by SEM. An $a g-2$ flower (A), and a $c l v 1-1$ ag-2 flower (B) from which most organs have been removed are shown. Note the $c l v 1-1 a g-2$ flower has started to fasciate. (C) A portion of a fasciated floral meristem of an older clv1-1 ag-2 flower from which most organs have been removed. (D) An older clv1-1 ag-2 flower, from which organs on one side have been removed, displaying progressively increasing fasciation. Bars, $10 \mu \mathrm{m}(\mathrm{A}, \mathrm{C})$ and $100 \mu \mathrm{m}(\mathrm{B}, \mathrm{D})$. All plants carried the erecta mutation.

Table 3. Floral organs counts for ag-2 and clv1-1 ag-2

\begin{tabular}{lccr}
\hline Whorl & Organ type & ag-2 & clv1-1 ag-2 \\
\hline Whorl 1 & Sepals & $4.0 \pm 0$ & $4.1 \pm 0.4$ \\
Whorl 2+3 & Petals & $9.8 \pm 0.5$ & $11.7 \pm 0.9$ \\
Whorl 4 & Sepals & $3.8 \pm 0.4$ & $4.7 \pm 0.7$ \\
Whorl 5+6 & Petals & $8.3 \pm 1.6$ & $13.0 \pm 1.1$ \\
Whorl 7 & Sepals & $2.2 \pm 0.6$ & $5.5 \pm 0.8$
\end{tabular}

The number of floral organs in each whorl of 40 ag-2 and clv1-1 ag-2 flowers were counted. Adjacent petal whorls were combined due to the difficulty in distinguishing between the two whorls. The mean number of indicated organs is shown with the standard error. Filaments were occasionally observed in the petal whorls: whorl 2 and 3 organ numbers include 0.08 filaments/flower for $a g-2$ and 1.3 filaments/flower for $c l v 1-1$ ag-2; whorl 5 and 6 organ numbers include 0.03 filaments/flower for $a g-2$ and 0.05 filaments/flower for clv1-1 ag-2. All plants carried the erecta mutation. flowers was the phenotype shown in Fig. 9D,F,H. In these flowers the gynoecium fused normally, and a large growth burst through it (Fig. 9F,G). A close examination of this growth showed that it had a characteristic meristem appearance (Fig. 9H, cf. Figs 1H, 7D, 12G and 14B).

\section{clavata1 mutants have altered patterns of AGAMOUS expression}

$A G$ controls the organ identity of the stamens and carpels, and consistent with its domain of function, $A G$ is expressed in the developing third and fourth whorls (which give rise to stamens and carpels) beginning at stage 3 (Drews et al., 1991). Because $c l v 1$ flowers are also somewhat indeterminate, in that they produce additional whorls compared to wild-type flowers, we were interested in examining the expression of $A G$ in $c l v l$ flowers. Wild-type, $c l v 1-1$ and 

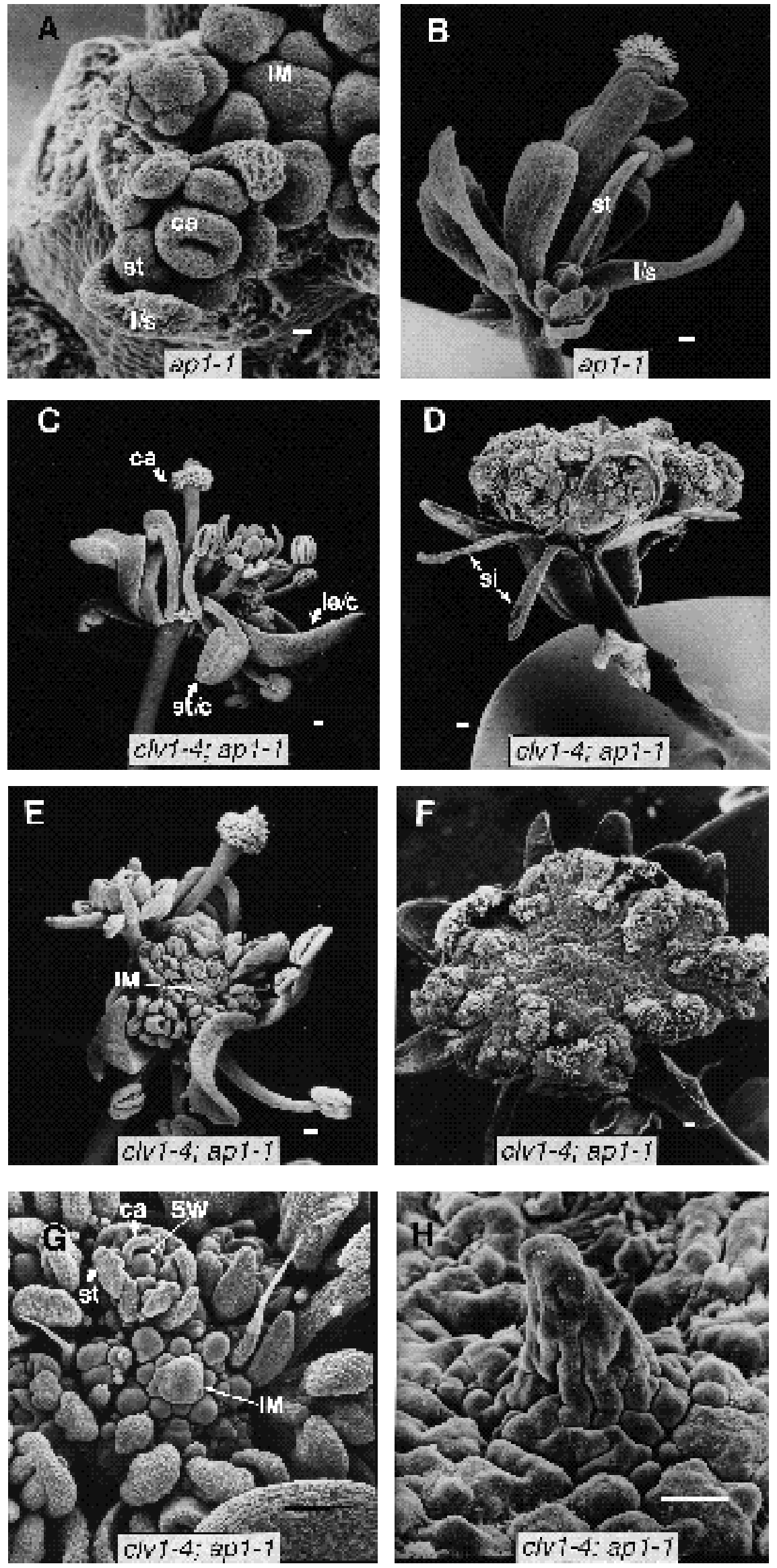
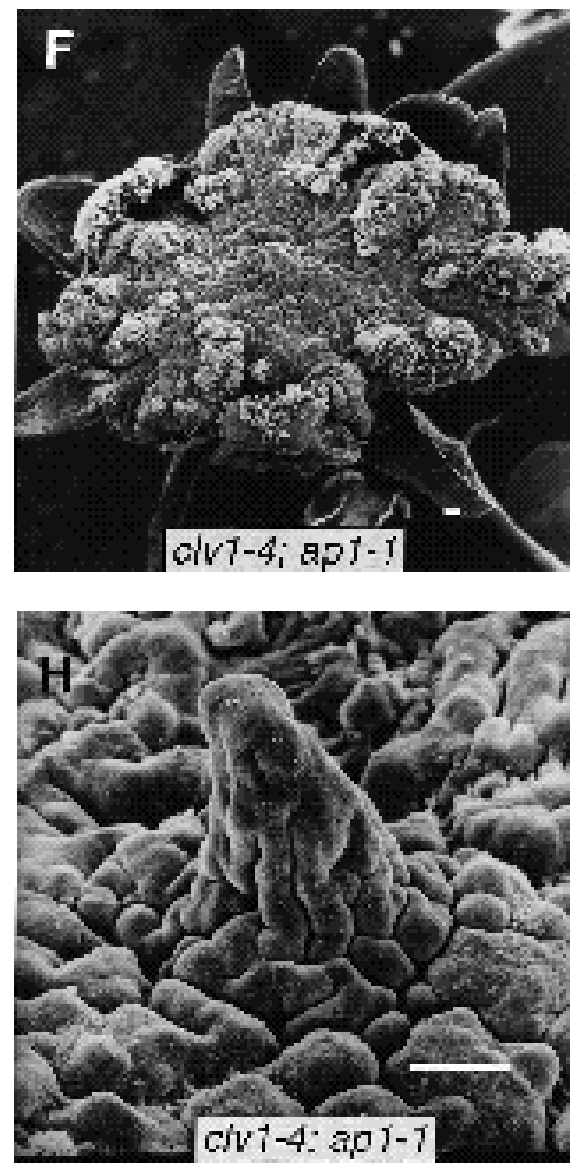

Fig. 9. clavatal apetalal double mutant plants. ap 1-1 (A,B), and clv1-4 apl-1 (C$\mathrm{H})$ plants were prepared as described and examined by SEM. ap 1-1 inflorescence and stage 6 flower (A), and mature flower (B) are shown. clv1-4 ap 1-1 flowers with an inflorescence meristem (C,E,G) and meristem tissue $(\mathrm{D}, \mathrm{F}, \mathrm{H})$ in the center of the flower are shown in side (C,D), top (E,F) and close-up $(\mathrm{G}, \mathrm{H})$ views. Note in $\mathrm{C}$ the staminoid, leaf-like or free-standing nature of the fourth-whorl carpels. G reveals that the center of the clv1-4 apl-1 flower (E) indeed contains an inflorescence meristem. This meristem has generated a number of young flowers including one in which the stamens (st), carpels (ca) and fifth whorl (5W) are indicated. Note in $\mathrm{H}$ the similarity to meristem tissue shown in Figs 1H, 7D, $12 \mathrm{G}$ and 14B. IM, inflorescence meristem; 1/s, leaf-like sepal; st, stamen; ca, carpel; st/c, staminoid carpel; le/c, leaf-like carpel; si, silique coat; $5 \mathrm{~W}$, fifth whorl. Bars, $10 \mu \mathrm{m}$ (A) and $100 \mu \mathrm{m}$ for all other panels. All plants carried the erecta mutation. 
clv1-4 flowers were fixed, sectioned and hybridized with a labeled $A G$ probe (see Materials and methods). Fig. 10 shows the pattern of $A G$ expression observed. In wild-type flowers, $A G$ was expressed in the center of the flower in cells that will later develop into the stamens (whorl 3) and carpels (whorl 4; Fig. 10A,D,G). clv1-1 and clv1-4 flowers lacked $A G$ expression in the center of the developing flower at the earliest stages of $A G$ expression (Fig. 10B,C). $A G$ was expressed in the portion of the clvl flower primordia that would have developed into the third and fourth-whorl organs, but not in the cells in the very center of the flower. In stage 6 clvl-1 and clv1-4 flowers, $A G$ expression continued to be restricted to the stamens and fourth-whorl carpels, and was not present or was present at reduced levels in the fifth whorl (Fig. 10E,F). By stage 8, $A G$ expression was detected in the fifth whorl of $c l v l-1$ flowers (Fig. 10H), but $c l v 1-4$ flowers continued to lack $A G$ expression at the tip of the still-proliferating floral meristem even at stage 12 (Fig. 10I,L), while stage $12 \mathrm{clv} 1-1$ flowers expressed AG throughout the gynoecium (Fig. 10J).

\section{clavata1 mutants have altered patterns of APETALA1 expression}

The expression of APETALAl (APl) is thought to be negatively regulated by $A G$ (Mandel et al., 1992). API expression appears throughout stage 1 and 2 flowers, preceding the expression of the homeotic genes $A G, A P 3$ and PI (Mandel et al., 1992; Drews et al., 1991, Jack et al., 1992; K. Goto and E. M. M., unpublished data). This expression then becomes restricted to the first and second whorls, coinciding with the emergence of $A G$ expression in the third and fourth whorls in stage 3 flowers.

Because $c l v 1$ affects $A G$ expression, and because clvl apl plants exhibit a non-additive phenotype, the expression of $A P 1$ was examined in clvl flowers. Sections of wild-type, clv1-1 and $c l v 1-4$ flowers were hybridized with a labeled $A P 1$ probe, and the results are shown in Fig. 11. At stages 1 and 2, expression in $c l v 1-1$ and $c l v 1-4$ flowers mirrored that in wild-type flowers (i.e. expression was observed in the entire flower primordium; Fig. 11A-C). As AP1 expression in wild-type flowers is lost from the third and fourth whorls, clvl flowers displayed a retention of $A P 1$ expression in the center of the flower, but not in the cells that would have given rise to whorls 3 and 4 . $A P 1$ expression in the fifth whorl of $c l v 1-1$ flowers was low, but consistently observed in stage 6 flowers (Fig. 11E,G,H). This low level of expression persisted until about the stage that $A G$ expression was observed in the fifth whorl (see Fig. 10H). In clv1-4 flowers, the center of stage 3 flowers clearly retained $A P 1$ expression (Fig. 11F), but, APl expression was not detected in the fifth whorl of stage $6 \mathrm{clvl-4}$ flowers (Fig. 11I).

\section{CLAVATA1 interacts with LEAFY to establish floral meristem identity}

The $L E A F Y(L F Y)$ locus is involved in establishing floral meristem identity (Schultz and Haughn, 1991; Weigel et al., 1992; Huala and Sussex, 1992). lfy- 1 plants produce extra cauline leaves before generating flowers. In addition, the flowers have some shoot meristem qualities: they are subtended by bracts, and the organs initiate in a slightly spiral pattern, rather than in perfect whorls (Weigel et al.,
1992; Fig. 12A). The flowers consist of sepals and poorly fused carpels. The double mutant combination of clv1-1 lfy$l$ was additive (Fig. 12B).

Unexpectedly, clv1-4 lfy-1 double mutant plants displayed a more severe phenotype. After vegetative growth, the clvl-4 lfy-l plants generated only five to 15 'flowers', and produced hundreds of filamentous organs and bracts (Figs 13 and 12C). The flowers that were generated showed severe defects and could only loosely be characterized as flowers. First, all traces of a whorled pattern of organ initiation were absent (Fig. 12D). Second, the sepals were leaf-like: they were often flanked by stipules at their base, and they produced stellate trichomes (Fig. 12E). Third, internode elongation was often observed between the spirally initiated organs (Fig. 12E,F). Interior leaf-like organs were often tipped with stigmatic tissue, but lacked other carpel characteristics, such as ovules (Fig. 12E). Finally, the floral meristems were indeterminate and continued to generate leaf-like organs (Fig. 12E,F). In all, the 'flowers' had far more shoot characteristics than floral characteristics, demonstrating that clvl-4 lfy-1 double mutant plants display a more severe phenotype than lfy- 1 single mutant plants in terms of the transformation of flowers into shoot structures. clvl-4 lfy-1 plants demonstrate a clear disruption in floral meristem identity. The fact that clv1-1 lfy-1 plants do not exhibit this defect suggests that $L F Y-C L V 1$ interactions are sensitive to the level or quality of CLV1 activity.

clv1-4 lfy-6 er plants were also analyzed (Note: lfy-1 and lfy-6 have identical lesions, CAG to TAG at codon 32). As shown in Fig. 12G, lfy- 6 enhanced the extent of meristem proliferation of $c l v 1-4$ in an er background. In addition, secondary meristems became fasciated (Fig. 12H). The only other difference between clv1-4 lfy-1 and clv1-4 lfy- 6 er plants was that 'flowers' of the latter occasionally contained

Fig. 10. AGAMOUS RNA expression in wild-type and clavatal plants. Landsberg (A,D,G), clvl-1 (B,E,H,J) and $c l v 1-4$

$(\mathrm{C}, \mathrm{F}, \mathrm{I}, \mathrm{K}, \mathrm{L})$ inflorescences were fixed, sectioned and hybridized with labeled $A G$ probe as described (see Materials and methods). All panels except $\mathrm{K}$ are bright-field/dark-field double exposures. Dark-field exposures were taken with a red filter to visualize the signal. In wild type, $A G$ expression first appears in stage 3 flowers (A) in the center of the flowers in the anlage for stamens and carpels. $A G$ expression continues to be present during stamen and carpel development (D,G). In $c l v 1-1$ (B) and $c l v 1-4$ (C) stage 3 flowers, $A G$ expression is not present in the center of the flower, but is present in the region of whorls 3 and 4 . As clvl-1 flowers continue to develop, $A G$ expression is lower or absent from the fifth whorl (E) until about stage $8(\mathrm{H})$, where it begins to be clearly expressed in the fifth whorl. J shows a late $c l v 1-1$ flower expressing $A G$ throughout the gynoecium, including the fifthwhorl carpels. In contrast, as clv1-4 flowers continue to develop, $A G$ is never expressed in the very center of the flower. It is absent from the top of the fifth whorl in stage 6 and stage 8 flowers as shown $(\mathrm{F}, \mathrm{I})$. This proliferative dome eventually gives rise to fifth and sixth whorl carpels. K shows an approximately stage 12 flower, and $A G$ expression in the proliferative dome is shown in $\mathrm{L}$. Even at this late stage, $A G$ is expressed at the base of this proliferative dome, but not at the tip. se, sepal; pe, petal; st, stamen; ca, carpel; 5W, fifth whorl; 4C, fourth-whorl carpel; 5C, fifth-whorl carpel. All plants carried the erecta mutation. Bars, 20 $\mu \mathrm{m}$. 

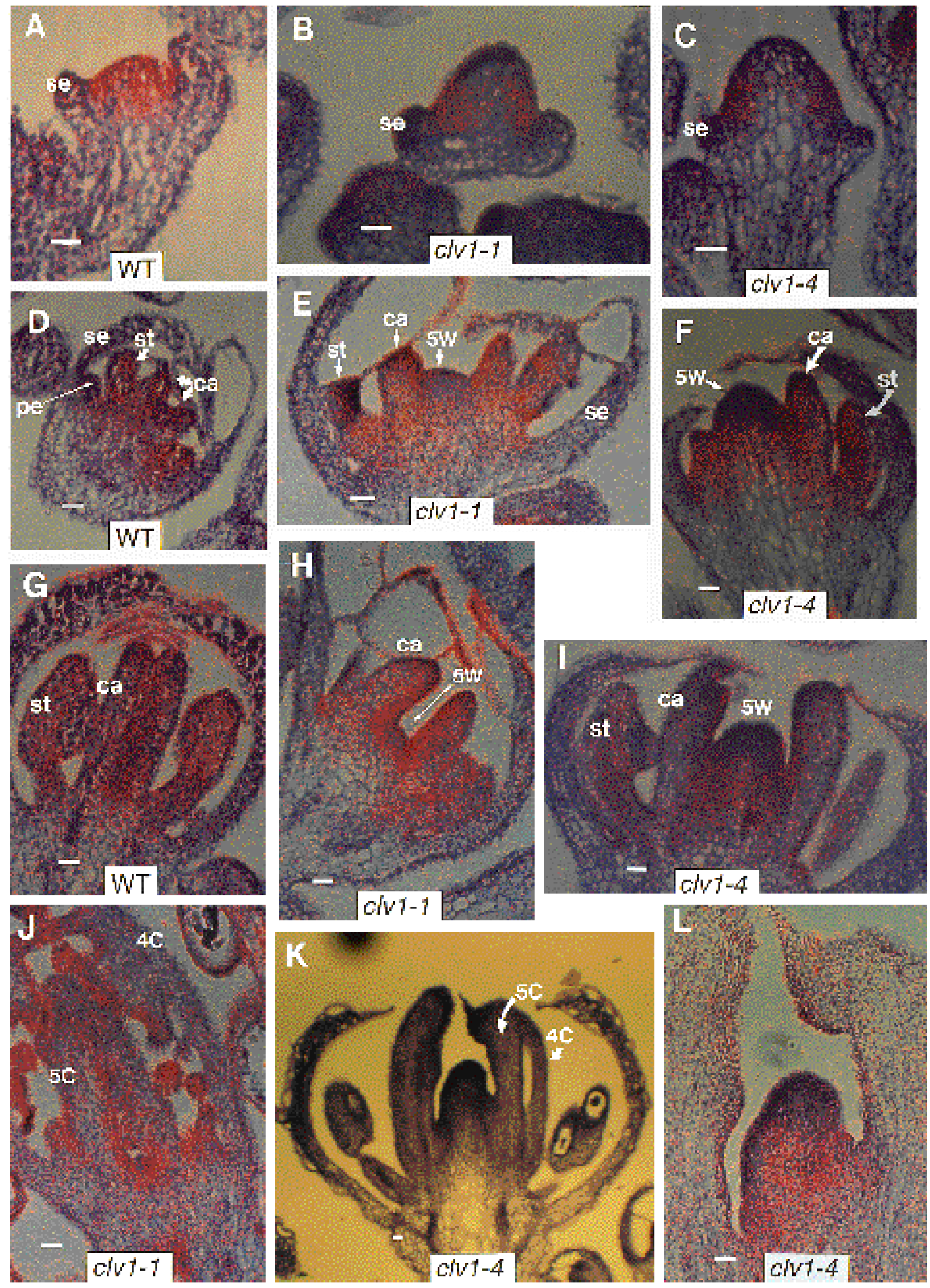

Fig. 10. For legend see p. 409

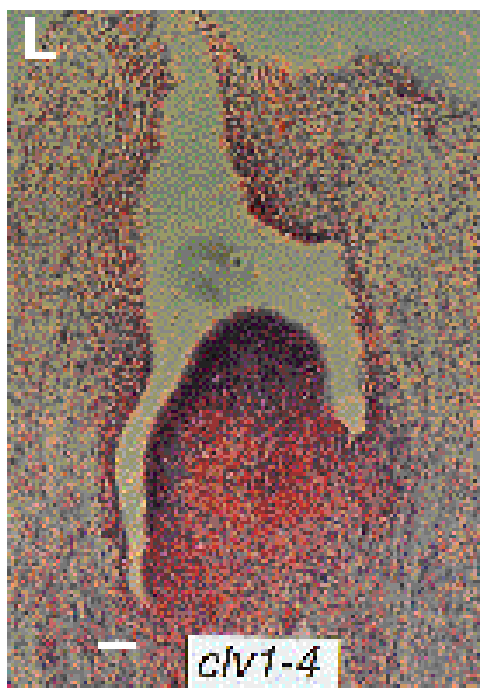

(19. 

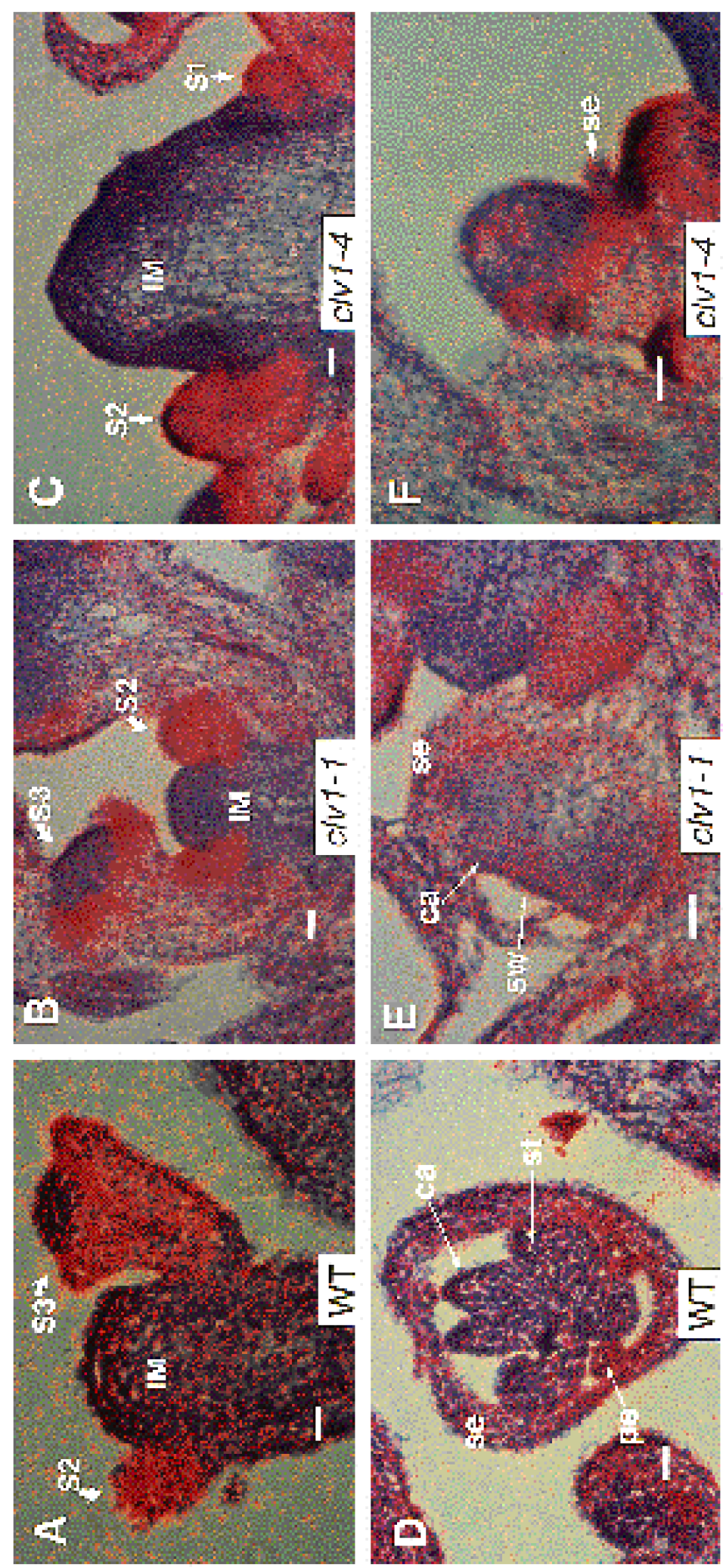
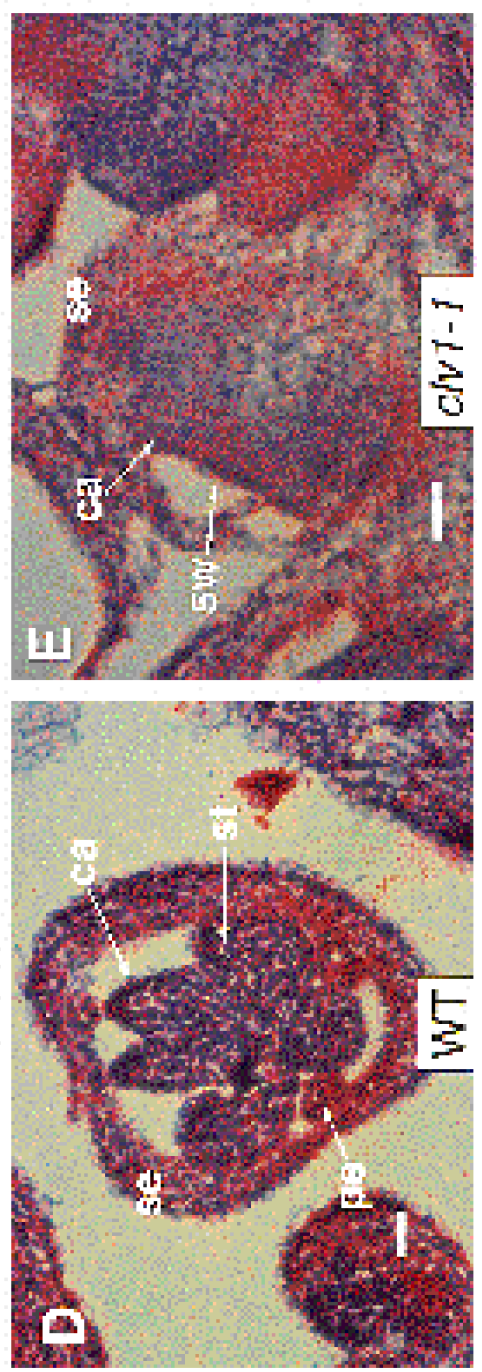
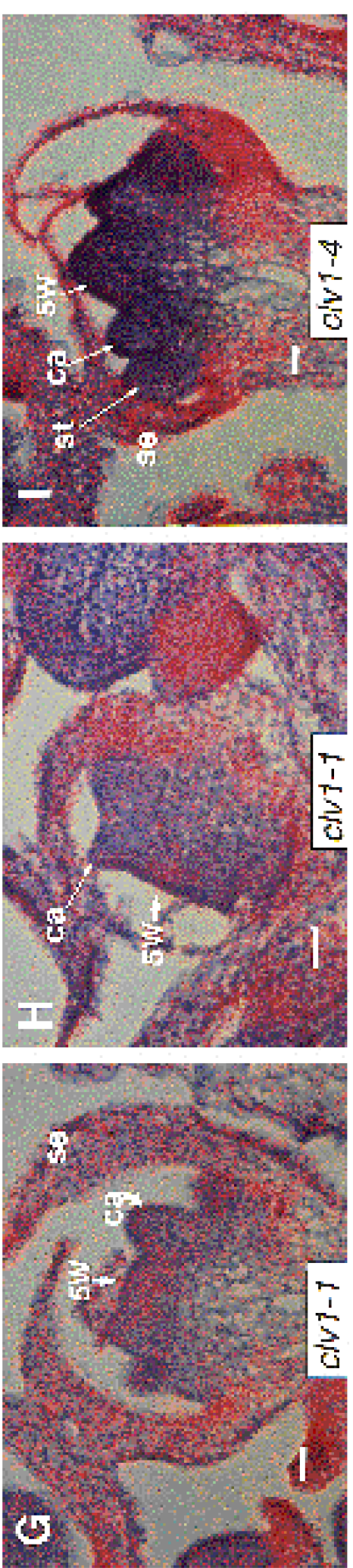

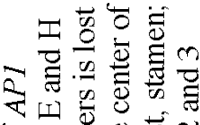

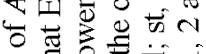

虫

응 $\frac{1}{2}$

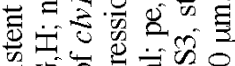

कo 0 क ज्ञ

ठิ

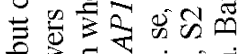

言要表的吉

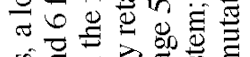

क

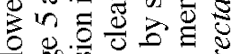

\& 80

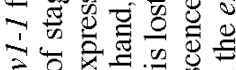

웡

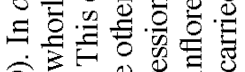

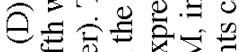

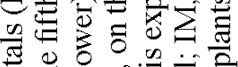

월 을

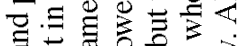

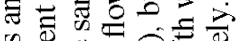

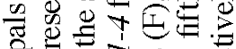

क्षे

$\circ \cdot \overline{0} \infty$

क्ष

娄

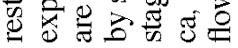

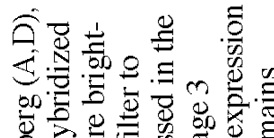

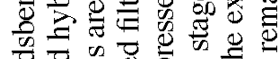

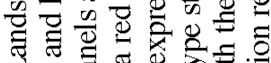

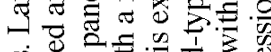

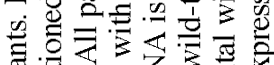
들 鸟

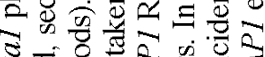
छ

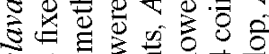
c

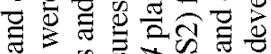

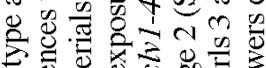

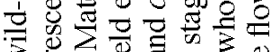

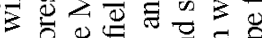

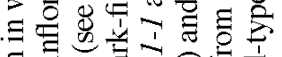

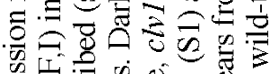

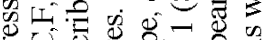

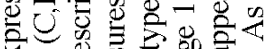

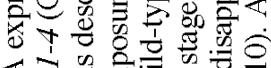

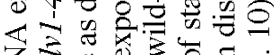
दे 늘

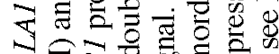

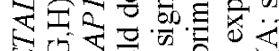
더웡 ำ

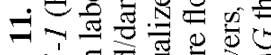

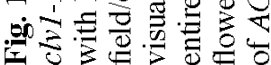



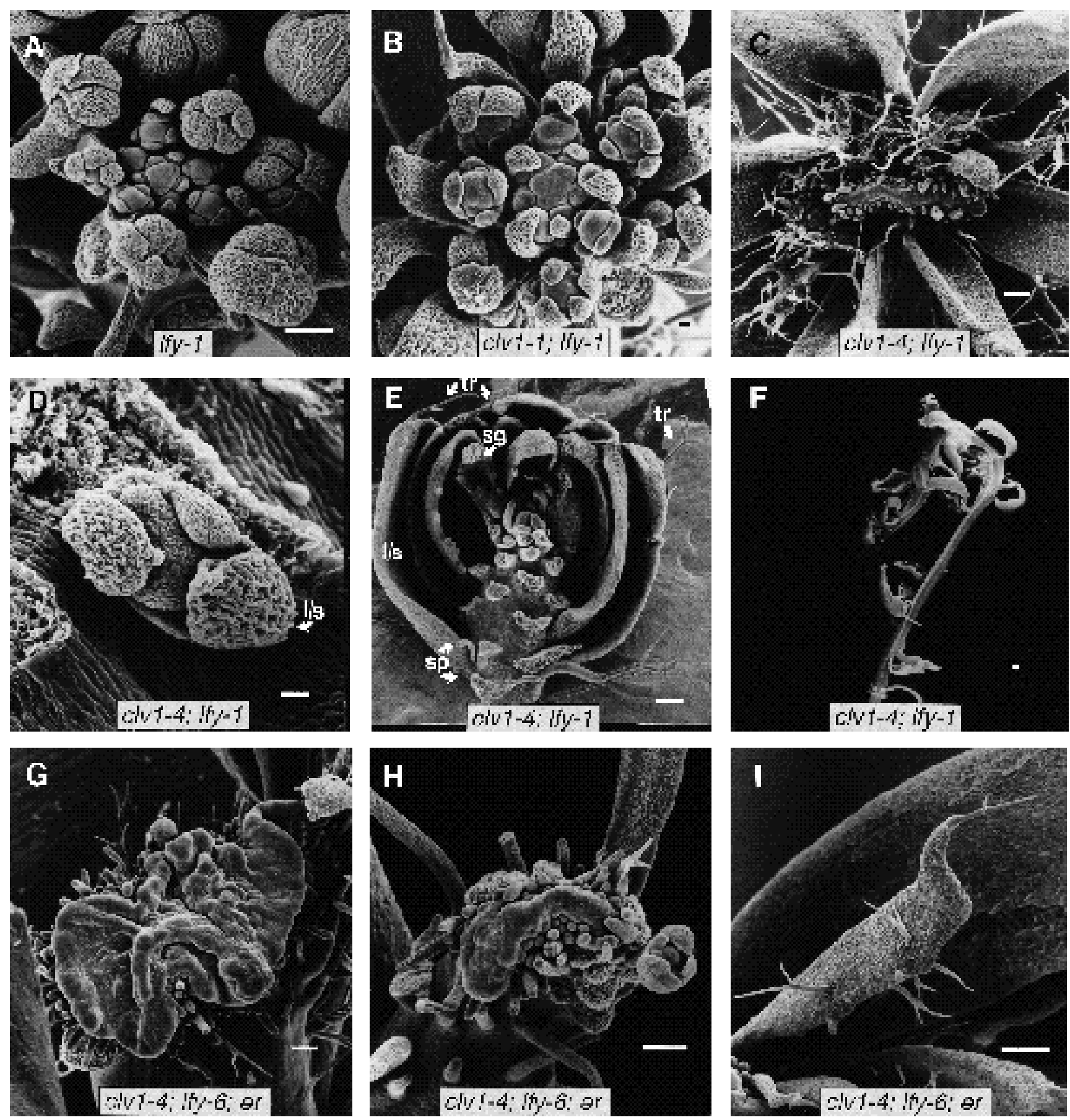

Fig. 12. clavatal leafy double mutant plants. lfy-1 (A), clv1-1 lfy-1 (B), clv1-4 lfy-1 (C-F) and clv1-4 lfy-6 er (G-I) plants were prepared as described and examined by SEM. Top views of inflorescence meristems of $l f y-1$ (A) and clvl-1 lfy-1 (B) reveal these plants generate flowers. A top view of a clvl-4 lfy-1 inflorescence (C) meristem reveals only developing bracts and filamentous structures. Very young clv1-4 lfy-1 flowers (D) exhibit complete spiral phyllotaxis of organ initiation. A clv1-4 lfy-1 flower, from which several leaf-like sepals have been removed (E), displays many shoot characteristics (see text). A much older clv1-4 lfy-1 flower (F) exhibiting continued floral proliferation is also shown. $c l v 1-4$ lfy-6 er apical meristems become massively proliferative (G), and clvl-4 lfy-6 er secondary inflorescence meristems become fasciated (H). In $c l v 1-4$ lfy-l and clv1-4 lfy-6 er plants, bracts with ' $\mathrm{S}$ ' curve tips are occasionally observed (I). 1/s, leaf-like sepal; sp, stipules; sg, stigmatic tissue; tr, stellate trichomes. Bar, $10 \mu \mathrm{m}$ (D) and $100 \mu \mathrm{m}$ for all other panels.

ovules on the margins of the carpelloid leaves (data not shown). Bracts with a ' $S$ ' curve at their tip were observed in $c l v 1-4 l f y-6$ er (Fig. 12I) and $c l v 1-4 l f y-1$ plants.

\section{clv1 ap1 Ify triple mutants}

The flowers of ap 1-1 lfy-6 plants also display shoot characteristics: they develop spirally initiated organs, the flowers 
are indeterminate, and the floral organs are either leaf-like or carpelloid (Weigel et al., 1992). Because clv1-4 lfy-6 plants exhibit a flower-to-shoot transformation similar to that seen ap 1-1 lfy- 6 plants, we sought to determine the role of $A P 1$ in the phenotype of clv1-4 lfy- 6 plants by examining clv1-4 ap 1-1 lfy-6 triple mutant plants. The apical meristems of clv1-4 apl-1 lfy-6 plants not only exhibited the overproliferation of the inflorescence meristem seen in clv1-4 lfy- 6 plants, but also developed tall meristem protrusions, often reaching $300 \mu \mathrm{m}$ in height (Fig. 14B). When compared to clv1-4 lfy-6 plants, clv1-4 ap 1-1 lfy-6 plants developed more bracts instead of filamentous organs, and more secondary inflorescences and 'flowers' in the axils of these bracts (Fig. 13), which suggests that $A P 1$ acts to suppress these structures in clv1-4 lfy-6 plants. clv1-4 apl-1 lfy-6 flowers also exhibit a more complete transformation to shoot structures than apl-1 lfy-6 flowers (Fig. 14C,D). clv1-4 apl-1 lfy-6 secondary inflorescence meristems became fasciated (Fig. 14E), and clv1-4 apl-1 lfy-6 primary inflorescences occasionally developed bracts with ' $\mathrm{S}$ ' curves at their tips (Fig. $14 \mathrm{~F})$.

\section{DISCUSSION}

We have investigated the effects of mutations in the CLAVATA 1 locus on Arabidopsis development. clv1 mutant plants have enlarged apical and floral meristems, leading to a variety of phenotypes including fasciation, disrupted phyllotaxis, and extra floral organs and whorls. Double mutant combinations with the homeotic genes $A G, A P 2, A P 3$ and $P I$ reveal that $C L V I$ controls the underlying floral meristem structure upon which the homeotic genes act. CLVI is the first Arabidopsis gene described in detail to affect floral meristem structure and floral organ number without affecting floral organ identity. clvl flowers also have altered patterns of $A G$ and $A P I$ expression. Mutant combinations with the meristem identity genes $A P l$ and $L F Y$ reveal that $C L V 1$ also plays a role in the determination and maintenance of floral meristem identity. CLVI may also be necessary for the delayed transition to flowering under short day conditions.

\section{CLV1 affects apical meristem structure}

The clvl alleles differ in their effects on apical meristem structure. First, all $c l v 1$ alleles enlarge the apical meristem during vegetative growth, although the strongest allele, clv14 , causes noticeably greater enlargement than the other alleles. As the vegetative growth of the plant progresses, leaf primordia are generated much farther down from the tip of the apical meristem in $c l v 1$ plants than in wild-type plants. As clv1 plants make the transition from vegetative to floral growth, more phenotypic differences between alleles become clear. clv1-5 inflorescence meristems (IMs) are simply enlarged compared to wild-type IMs. clv1-1 IMs undergo fasciation, while clv1-4 IMs can, especially at $16^{\circ} \mathrm{C}$, develop into a massive meristem growth.

In the nineteenth century, a debate raged over the nature of fasciation. Linneaus had, in 1751, proposed that fasciation was the result of the fusion of buds resulting from crowding. His view was later supported by Hincks (1855) and Masters (1869). Moquin-Tandon (1841) put forward a different model, namely that fasciation was caused by the transformation of a single growing point into a line. This model found many supporters including Nestler (1894) and Schoute (1936). It appears that in order to dismiss rare cases where stem fasciation was clearly the result of the fusion of buds (Franke, 1880), Nestler (1894) first proposed, and Schoute (1936) supported, the consideration of these cases as aberrations. In their definition, true or typical fasciations were those where fasciation occurred in accordance with their model (i.e. the transformation of a single growing point into a line), while any examples where the fusion of buds caused fasciation were not considered real fasciation, and were referred to as connation. While this distinction is artificial considering the lack of evidence on the origin of fasciation in the overwhelming majority of cases, it seems to have become accepted by at least one recent reviewer (Gorter, 1965). Our experiments give a detailed description of one type of inherited fasciation, which does not appear to occur by bud fusion. Morphologically, the $c l v 1$ apical meristem is transformed from a point to a line $(c l v 1-1)$ or a large mass ( $c l v 1-4)$. If we accept the classical view that the apical meristem is divided into a central zone (CZ) of slowly dividing cells that replenish a surrounding peripheral zone (PZ) where organ initiation occurs, then clvl apical meristems represent an enlargement of the $\mathrm{CZ}$, because the region where organ initiation does not occur is much larger in $c l v 1$ apical meristems than in wild type. However, it is curious that fasciation occurs in $\operatorname{clv} 1-1$ not by simple enlargement of the apical tip, but by extensions of the apical meristem in the region where organs are being initiated (i.e. the putative $\mathrm{PZ}$ region). In addition, mutations in $L F Y$ and $A P 1$ enhance fasciation and meristem proliferation in $c l v l$ (Figs 12 and 14), despite the fact that these genes are not expressed in the apical meristem, but instead are expressed in nascent floral primordia.

\section{CLV1 affects floral meristem identity}

Double mutant combinations of $c l v l$ with apl and lfy reveal that $C L V 1$ plays a previously unsuspected role in the determination and maintenance of floral meristem identity. In the case of clvl apl double mutants, nascent floral primordia are correctly specified, but cells in the center of these flowers can become specified as an inflorescence meristem. Thus, CLV1 may contribute to the maintenance of floral meristem identity in a portion of the wild-type flower. This hypothesis is consistent with the observation that $c l v 1-4$ flowers contain meristem-like tissue, though not an inflorescence meristem, at their centers. Because in $c l v 1-1$ and clv1-4 flowers APl is expressed in cells that adopt an inflorescence meristem fate in clvl apl-1 flowers, it is tempting to speculate that $A P 1$ expression maintains the floral meristem identity of the fifth whorl. Thus, when APl activity is removed, these cells adopt an inflorescence meristem fate. This misexpression of $A P 1$ is likely due to the lack of $A G$ expression in the center of $c l v 1$ flowers, although it is interesting to note that the fifth whorl of stage $6 \mathrm{clvl}-4$ flowers express neither $A G$ nor $A P 1$. The lack of $A G$ and $A P l$ expression in the center of $c l v 1-4$ flowers may lead these cells to adopt a meristem fate. It is possible that the expression of $A P 1$ in the fifth whorl of stage 6 clvl-1 

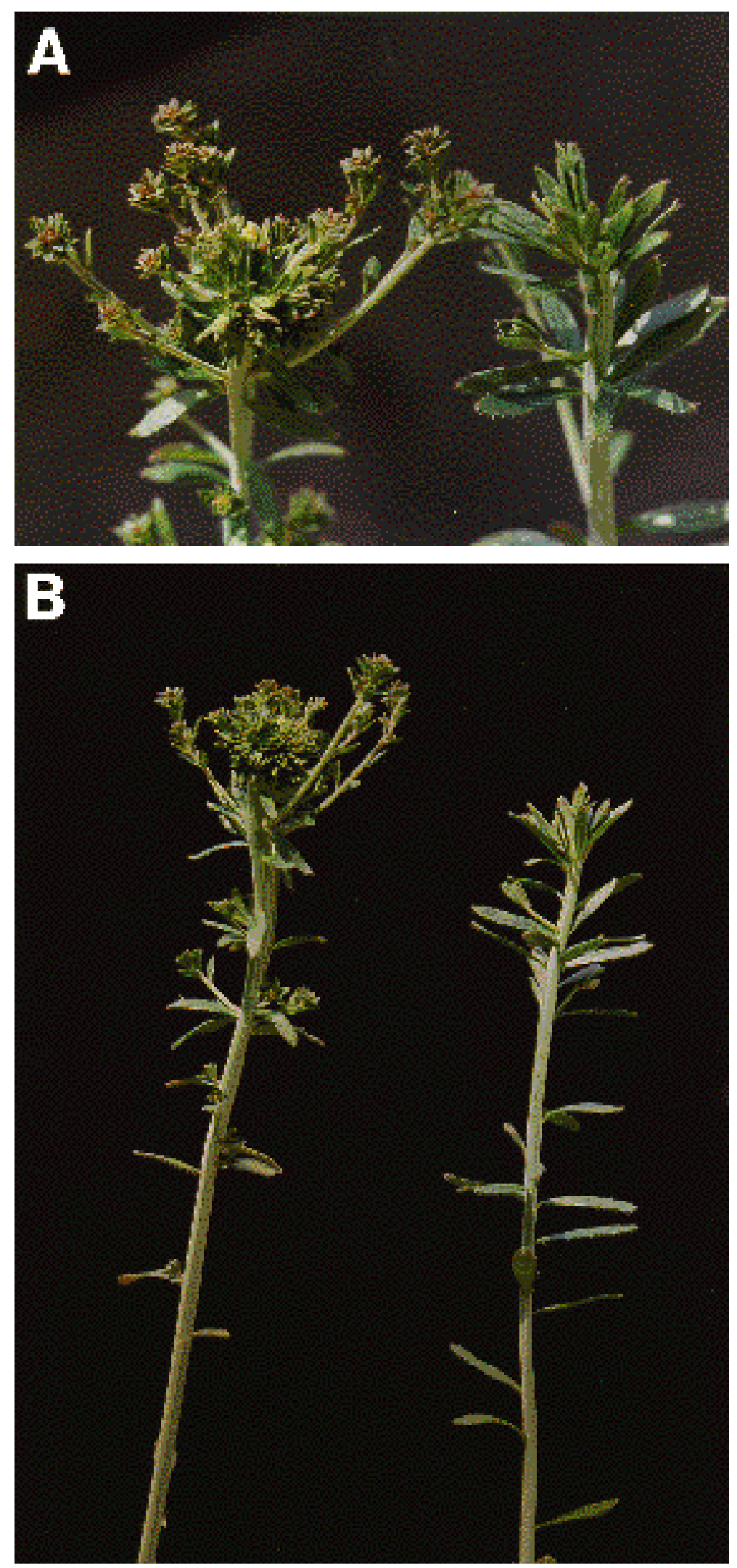

Fig. 13. Comparison of clavatal leafy and clavatal apetala1 leafy plants. clv1-4 lfy-6 (right) and $c l v 1-4$ ap1-1 lfy-6 (left) plants were grown as described and photographed. A shows a close-up of the top of the inflorescences, while B shows the entire inflorescence. clv1-4 ap 1-1 lfy-6 inflorescences generate more bracts, secondary inflorescences and transformed flowers than clv1-4 lfy-6 inflorescences. Both plants carried the erecta mutation and were the same age. flowers helps prevent further proliferation of these cells into the meristem-like tissue seen in clv1-4 flowers (which do not exhibit this $A P l$ expression). While $A P 1$, as pointed out, is not expressed at the center of stage $6 \mathrm{clvl}-4$ flowers, it is possible that its earlier misexpression in the center of stage 3 clv1-4 flowers reduces the overall growth of these 
cells, or reduces the number of cells adopting a meristem fate.

Another example of the role of CLVI in floral meristem identity is seen in the double mutant clv1-4 lfy-1. In this double mutant, very few floral primordia develop. Instead, most of the primordia generated by the inflorescence meristem are converted into filamentous organs and bracts. Those floral primordia that are generated develop into structures with very few floral characteristics and appear to be almost completely transformed into shoot meristems. The shoot characteristics of these flowers include spirally initiated organs, indeterminacy, and leaf-like organs with stipules and stellate trichomes. Thus the generation of flowers is almost blocked by mutations in these two genes. Hypotheses concerning the nature of $C L V 1-L F Y$ interactions depend on the mechanism of $C L V I$ action, and will be discussed below.

Further evidence of the role $C L V 1$ plays in floral meristem specification comes from observations of clv1-4 apl-1 lfy-6 triple mutant plants. Here we find that the flowers generated are more completely transformed into shoot structures than ap 1-1 lfy-6 flowers (Fig. 14). In addition, clv1-4 ap1-1 lfy6 plants develop more secondary inflorescences and transformed flowers than clv1-4 lfy-6 plants (Fig. 13). This implies that the deficit in flower and secondary inflorescence development in clv1-4 lfy-6 plants is not due to some defect in organ development caused by the clvl-4 and lfy-6 mutations, but rather appears to be the result of the suppression of these structures by $A P 1$ function.

\section{CLV1 affects floral meristem structure}

We have shown that clvl floral primordia are larger and develop more organs than wild-type flowers. CLV1 is the first locus described to affect organ number and not organ identity. At the earliest stage of floral organ initiation (stage 3 ), the clvl floral meristem is already significantly taller than that of wild-type stage 3 flowers (Fig. 6). The enlargement of the portion of the floral meristem in $c l v l$ giving rise to whorls 3 and 4 in wild-type flowers correlates with and presumably causes the generation of additional organs in these whorls. Perhaps the anlage for whorls 3 and 4 are more affected than the anlage for whorls 1 and 2, because the clv 1 floral meristem is more affected in height than width. This might explain why whorls 3 and 4 exhibit a greater increase in organ number than whorls 1 and 2 .

The mechanism responsible for floral meristem enlargement in clvl plants is unclear. Results of in situ hybridization experiments demonstrate that stage $3 \mathrm{clv} l$ flowers lack $A G$ expression at their center. Thus, one explanation for a taller floral meristem is that the absence of detectable $A G$ expression in the center of the flower results in continued proliferation of these central cells. While this hypothesis would agree with observations that $A G$ controls the determinacy of the floral meristem (Bowman et al., 1989), we consider it unlikely to be the only mechanism, for three reasons. First, the mutant floral meristem is already larger than the wild-type floral meristem at stage 3 when $A G$ is first expressed. Second, $A G$ is not expressed in the first or second whorls of $c l v 1$ or wild-type flowers, yet these whorls exhibit extra organs in $c l v 1$ flowers. Third, $a g$ is not epistatic to $c l v 1$ : clv1-1 increases organ number in an ag-2 background and causes floral meristem fasciation, which is not seen in $a g-2$ single mutants. These observations would suggest that CLVI controls floral meristem structure by acting independently as well as possibly acting through $A G$.

A second explanation for the enlarged floral meristem is that $c l v 1$ floral meristems are initiated with more cells than wild-type floral meristems. This hypothesis would not explain, however, why any additional cells would continue to proliferate throughout floral development, and why those cells at the center of the floral primordia would not express $A G$, unless $A G$ expression is triggered by some type of diffusion from the first or second whorl. A third explanation is that $c l v 1$ fails to control cell proliferation in general. It is unclear, though, why only cells in the center of the floral meristem would continue to proliferate.

It is interesting that while the number of additional organs in each whorl is quite variable, and that in any given flower any of the four whorls can exhibit the greatest number of additional organs, very few mosaic or hybrid organs were observed (data not shown). This observation suggests that whorl boundaries are rigidly maintained despite the fact that each whorl has a variable number of extra organs, presumably resulting from having a variable number of extra cells. It is also of interest that these larger floral primordia give rise to more organs, and not bigger organs.

Another interesting phenotype of $c l v 1$ flowers is the development of additional whorls interior to the fourthwhorl carpels. Despite the fact that wild-type flowers separate the floral primordia into only four whorls, the enlarged clvl floral primordia are divided into additional whorls, not just larger whorls. The flowers of weak and intermediate $c l v l$ alleles develop an additional whorl of carpels and then terminate, while clvl-4 flowers often develop two additional whorls of carpels and continue to develop meristem-like tissue. Whether this meristem-like tissue is simply the result of floral indeterminacy, the result of a partial transformation of the center of $c l v 1-4$ flowers into shoot identity, or something else entirely, is unclear.

\section{CLV1 may be necessary for short day flowering delay}

Normally, Arabidopsis thaliana grown under short day conditions experiences a significant delay in the transition to flowering (i.e. the vegetative growth phase is extended). While $\operatorname{clv1-1}$ plants exhibit this delay, clv1-4 plants were unaffected by short day conditions. This difference in allelic response to short day conditions is likely due to the severity of the clv1-4 allele, which exhibits clear differences from clv1-1 for every trait examined. It is possible, though, that this is due to a separate, linked mutation that was not separated during the three back crosses. Mutations at other loci have been identified that result in early flowering, including hyl, hy2, phyA and phyB(hy3) (Goto et al., 1991; Zagotta et al., 1992; Reed et al., 1993). These loci are necessary for the generation of phytochrome A and B for the red light photoreceptors.

\section{Mechanism of $C L V 1$ action}

Mutations in CLV1 disrupt floral meristem structure, inflorescence meristem structure, floral meristem identity and, apparently, timing of flowering under short day conditions. 

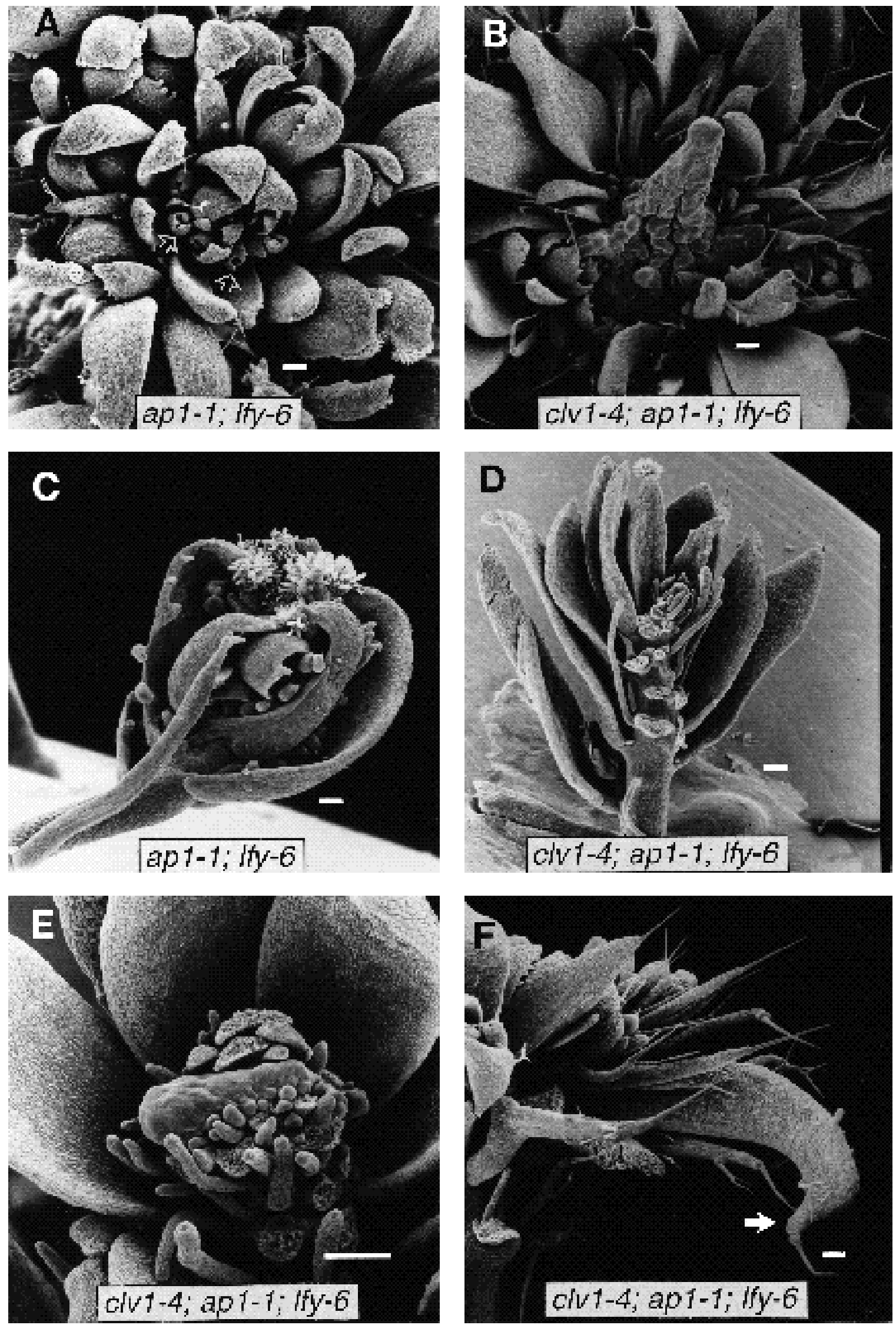

Fig. 14 
Fig. 14. clavatal apetalal leafy triple mutants. apl-1 lfy-6 (A,C) and clv1-4 apl-1 lfy-6 (B,D,E,F) inflorescences were prepared as described and examined by SEM. (A,B) A comparison of inflorescence meristems of ap 1-1 lfy-6 and clv1-4 ap 1-1 lfy-6 plants shown at the same magnification. Note the developing flowers (open arrows in A), and the protruding meristem tissue in B. (C,D) A comparison of ap 1-1 lfy-6 and clv1-4 apl-1 lfy-6 flowers shown at the same magnification. ap 1-1 lfy-6 flowers are partially transformed into shoots, but in clv1-4 apl-1 lfy-6 flowers this transformation is more complete. $c l v 1-4$ ap $1-1$ lfy- 6 secondary inflorescence meristems become fasciated (E). clv1-4 ap 1-1 lfy-6 plants develop bracts with ' $\mathrm{S}$ ' curve tips ( $\mathrm{F}$, closed arrow) similar to those found in clv1-4 lfy-6 plants. All plants carried the erecta mutation. Bars, $100 \mu \mathrm{m}$.

One possible mechanism of CLVI action, which we consider unlikely, is that $C L V 1$ plays a separate role in each of these developmental pathways.

A second possibility is that CLVI plays a role in cell division patterns. If proliferation of cells in the center of apical and floral meristems were controlled by CLVI activity, clvl mutants could result in enlarged inflorescence meristems and flowers with proliferating, unspecified tissue in the center. In addition, the floral identity specification imparted on lfy floral primordia may require strict control of cell division patterns to compensate for loss of $L F Y$ activity, leading to an almost complete loss of floral specification in clvl lfy double mutants. This model does not account for the possible $C L V 1$ function in short day flowering delay.

A third possibility is that $C L V 1$ plays a general role in signaling between plant cells. In this model, in developmental pathways in which this signaling is absolutely required, such as the establishment of inflorescence and floral meristem structure and the short day flowering delay, the role of CLV1 would be revealed in the clv1 single mutant. Other developmental pathways for which the CLVI signaling is not absolutely required, such as floral meristem identity, would reveal a $C L V I$ role only when other possibly redundant components in the signaling pathway were mutated. This signaling could be long- or short-distance. For example, the role of $A P I$ in lfy plants to establish partial floral meristem identity may require stage 1 flowers, expressing $A P 1$, to send a $C L V 1$-dependent signal to the adjacent floral anlage that would normally be expressing $L F Y$, or may require cell-to-cell transmission within a single floral primordium to overcome the effect of the lfy mutation in particular cells. In these scenarios, CLVI would not be required for floral meristem specification in wild-type plants, but would be required for floral meristem specification in lfy plants. Neither of the last two possibilities exclude the other, and CLV1 may play a role both in specifying cell division patterns by affecting cellular signals, or vice versa.

We thank our colleagues Detlef Weigel, Tom Jack, Gary Drews, Joshua Levin, Leslie Sieburth, Caren Chang, Hajime Sakai, Robert Williams, Jose-Luis Riechmann and Susan Apostolaki for critical review of the manuscript. We also thank Martin Yanofsky for providing us with the AP1 probe prior to publication, and Pat Koen of the Electron Microscope Facility at Caltech for technical advice. This work was supported by United States National Science Foundation (NSF) grant number MCB-9204839 to E. M. M. S. E. C. was supported by an NSF Postdoctoral Fellowship in Plant Biology, and M. P. R. was a Howard Hughes Predoctoral Fellow.

\section{REFERENCES}

Bateson, W. (1909). Mendel's Principles of Heredity. Cambridge: Cambridge University Press.

Bowman, J. L., Alvarez, J., Weigel, D., Meyerowitz, E. M. and Smyth, D. R. (1993). Control of flower development in Arabidopsis thaliana by APETALA1 and interacting genes. Development, in press.

Bowman, J. L., Smyth, D. R. and Meyerowitz, E. M. (1989). Genes directing flower development in Arabidopsis. Plant Cell 1, 37-52.

Bowman, J. L., Smyth, D. R. and Meyerowitz, E. M. (1991). Genetic interactions among floral homeotic genes of Arabidopsis. Development 112, $1-20$.

Brown, J. A. M., Miksche, J. P. and Smith, H. H. (1964). An analysis of $\mathrm{H}^{3}$-thymidine distribution throughout the vegetative meristem of Arabidopsis thaliana (L.) Heynh. Radiation Botany 4, 107-113.

Coen, E. S. and Meyerowitz, E. M. (1991). The war of the whorls: genetic interactions controlling flower development. Nature 353, 31-37.

Drews, G. N., Bowman, J. L. and Meyerowitz, E. M. (1991). Negative regulation of the Arabidopsis homeotic gene AGAMOUS by the APETALA2 product. Cell $\mathbf{6 5}, 991-1002$.

Emerson, R. A. (1911). Genetic correlation and spurious allelomorphism in maize. Ann. Rpt. Nebr. Agr. Exp. Sta. 24, 58-90 (quoted in White, 1916).

Franke, A. B. (1880). Die Krankheiten der Pflanzen. Breslau (quoted in Schoute, 1936)

Gorter, C. J. (1965). Origin of fasciation. In Encyclopedia of Plant Physiology. (ed. W. Ruhland) pp. 330-351. New York: Springer-Verlag.

Goto, N., Kumagai, T. and Koornneef, M. (1991). Flowering responses to light-breaks in photomorphogenic mutants of Arabidopsis thaliana, a long day plant. Physiol. Plant. 83, 209-215.

Hincks, W. (1855). Note on the nature of fasciated stems. Proc. Linn. Soc. 2 , 215 (quoted in Schote, 1936).

Huala, E. and Sussex, I. M. (1992). LEAFY interacts with floral homeotic genes to regulate Arabidopsis floral development. Plant Cell 4, 901-913.

Irish, V. F. and Sussex, I. M. (1990). Function of the apetala-1 gene during Arabidopsis floral development. Plant Cell 2, 741-751.

Jack, T., Brockman, L. L. and Meyerowitz, E. M. (1992). The homeotic gene APETALA3 of Arabidopsis thaliana encodes a MADS box and is expressed in petals and stamens. Cell 68, 683-697.

Koornneef, M., van Eden, J., Hanhart, C. J., Stam, P., Braaaksma, F. J. and Feenstra, W. J. (1983). Linkage map of Arabidopsis thaliana. J. Hered. 74, 265-272.

Leyser, H. M. O. and Furner, I. J. (1992). Characterization of three shoot apical meristem mutants of Arabidopsis thaliana. Development 116, 397 403.

Linnaeus, C. (1751). Philosophia Botanica. Stockholm: Apud Godofr. Kiesewetter.

Mandel, M. A., Gustafson-Brown, C., Savidge, B. and Yanofsky, M. F. (1992). Molecular characterization of the Arabidopsis floral homeotic gene APETALA1. Nature 360, 273-277.

Masters, M. T. (1869). Vegetable Teratology. London: Ray Society.

McKelvie, A. D. (1962). A list of mutant genes in Arabidopsis thaliana. Radiation Botany 1, 233-241.

Medford, J. I., Behringer, F. J., Callos, J. D. and Feldmann, K. A. (1992). Normal and abnormal development in the Arabidopsis vegetative shoot apex. Plant Cell 4, 631-643.

Mendel, G. J.(1866). Versuche uber Pflanzen-Hybriden. Verh. Naturf. Ver. Brunn 4, 3-47 (English translation by W. Bateson, 1909).

Mertens, T. R. and Burdick, A. B. (1954). The morphology, anatomy and genetics of a stem fasciation in Lycopersicon esculentum. Amer. J. Bot. 41, 726-732.

Meyerowitz, E. M., Bowman, J. L., Brockman, L. L., Drews, G. N., Jack, T., Sieburth, L. E. and Weigel, D. (1991). A genetic and molecular model for flower development in Arabidopsis thaliana. Development Supplement 1, 157-167.

Miksche, J. P. and Brown, J. A. M. (1965). Development of vegetative and floral meristems of Arabidopsis thaliana. Am. J. Bot. 52, 533-537.

Moquin-Tandon, A. (1841). Elements de teratologie vegetale. Paris: P.-J. Loss.

Nestler, A. (1894). Untersuchungen uber Fasciationen. Oesterr. Bot. Ztschr. 44, p. 343.

Reed, J. W., Nagpal, P., Poole, D. S., Furuya, M. and Chory, J. (1993). Mutations in the gene for the red/far-red light receptor phytochrome B alter cell elongation and physiological responses throughout Arabidopsis development. Plant Cell 5, 147-157. 
Satina, S., Blakeslee, A. F. and Avery, A. G. (1940). Demonstration of the three germ layers in the shoot apex of Datura by means of induced polyploidy in periclinal chimeras. Am. J. Bot. 27, 895-905.

Schoute, J. C. (1936). Fasciation and dichotomy. Rec. Trav. Bot. Neerl. 33, 649-669.

Schultz, E. A. and Haughn, G. W. (1991). LEAFY, a homeotic gene that regulates inflorescence development in Arabidopsis. Plant Cell 3, 771781.

Smyth, D. R., Bowman, J. L. and Meyerowitz, E. M. (1990). Early flower development in Arabidopsis. Plant Cell 2, 755-767.

Szymkowiak, E. J. and Sussex, I. M. (1992). The internal meristem layer (L3) determines floral meristem size and carpel number in tomato periclinal chimeras. Plant Cell 4, 1089-1100.

Tadulingam, C. and Jacob, K. C. (1925). Note on some examples of plant teratology from South India. J. Indian Bot. Soc. 4, 225-226.

Takagi, F. (1929). On the inheritance of some characters in Glycine soja Bentham (Soybean). Tohoku Imp. Univ., Sci Rep. IV 4, 577-589.

Vaughn, J. G. (1952). Structure of the angiosperm apex. Nature 169, 458459.

Vaughn, J. G. and Jones, F. R. (1953). Structure of the angiosperm inflorescence apex. Nature 171, 751-752.

Weigel, D., Alvarez, J., Smyth, D. R., Yanofsky, M. F. and Meyerowitz, E. M. (1992). $L E A F Y$ controls floral meristem identity in Arabidopsis. Cell 69, 843-859.

Weigel, D. and Meyerowitz, E. M. (1993). Activation of floral homeotic genes in Arabidopsis. Science, in press.
White, O. E. (1916). Studies of teratological phenomena in their relation to evolution and the problems of heredity. II. The nature, causes, distribution and inheritance of fasciation with special reference to its occurence in Nicotiana. Zeits. Ind. Abst. Ver. 16, 49-185.

White, O. E.(1948). Fasciation. Bot. Rev. 14, 319-358.

Yanofsky, M. F., Ma, H., Bowman, J. B., Drews, G. N., Feldmann, K. A. and Meyerowitz, E. M. (1990). The protein encoded by the Arabidopsis homeotic gene AGAMOUS resembles transcription factors. Nature 346, 35-39.

Young, P. A. and MacArthur, J. W. (1947). Horticultural characters of tomatoes. Texas Agr. Exp. Stat. Bull. No. 698.

Zagotta, M. T., Shannon, S., Jacobs, C. and Meeks-Wagner, D. R. (1992). Early-flowering mutants of Arabidopsis thaliana. Aust. J. Pl. Physiol. 19, 411-418.

(Accepted 1 July 1993)

\section{Note added in proof}

Observations of additional carpel development interior to the four whorl gynoecium in clvl flowers has recently been noted by Shannon and Meeks-Wagner (Plant Cell 5, 639655). 